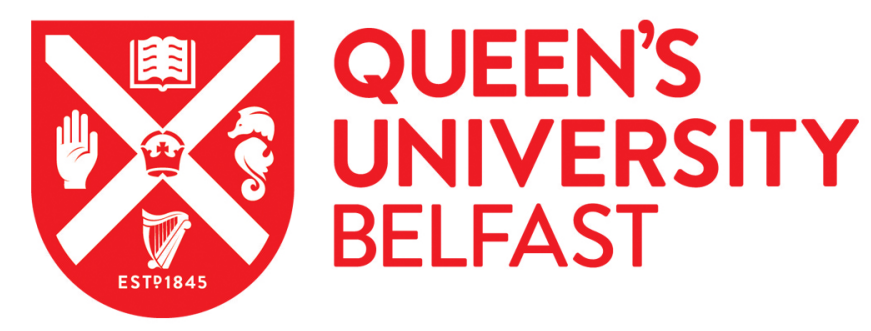

\title{
Comparing classical and Bayesian 210Pb dating models in human- impacted aquatic environments
}

Aquino-López,2M A., Ruiz-Fernández, A. C., Blaauw, M., \& Sanchez-Cabeza, J. A. (2020). Comparing classical and Bayesian 210 dating models in human-impacted aquatic environments. Quaternary Geochronology, 60, [101106]. https://doi.org/10.1016/j.quageo.2020.101106

Published in:

Quaternary Geochronology

Document Version:

Peer reviewed version

Queen's University Belfast - Research Portal:

Link to publication record in Queen's University Belfast Research Portal

Publisher rights

(C) 2020 Elsevier B.V.

This manuscript is distributed under a Creative Commons Attribution-NonCommercial-NoDerivs License

(https://creativecommons.org/licenses/by-nc-nd/4.0/), which permits distribution and reproduction for non-commercial purposes, provided the author and source are cited.

\section{General rights}

Copyright for the publications made accessible via the Queen's University Belfast Research Portal is retained by the author(s) and / or other copyright owners and it is a condition of accessing these publications that users recognise and abide by the legal requirements associated with these rights.

Take down policy

The Research Portal is Queen's institutional repository that provides access to Queen's research output. Every effort has been made to ensure that content in the Research Portal does not infringe any person's rights, or applicable UK laws. If you discover content in the Research Portal that you believe breaches copyright or violates any law, please contact openaccess@qub.ac.uk. 
1 Comparing classical and Bayesian ${ }^{210} \mathrm{~Pb}$ dating models in human2 impacted aquatic environments

3

4 Marco A. Aquino-López ${ }^{1}$, Ana Carolina Ruiz-Fernández², Maarten Blaauw³ , Joan-

5 Albert Sanchez-Cabeza ${ }^{2 *}$

6

$7 \quad{ }^{1}$ Maynooth University, Arts and Humanities Institute, Maynooth, Co. Kildare, Ireland.

$8{ }^{2}$ Unidad Académica Mazatlán, Instituto de Ciencias del Mar y Limnología, Universidad

9 Nacional Autónoma de México, 82040 Mazatlán, México

$10{ }^{3}$ School of Natural and Built Environment, Queen's University Belfast, Belfast, UK.

11

12 * Corresponding author: jasanchez@cmarl.unam.mx

13 


\section{Abstract}

15 Chronologies are an essential tool to place natural archives of environmental changes on a calendar scale. Because of this, studies that compare and assess the accuracy and precision of available dating models are essential. ${ }^{210} \mathrm{~Pb}$ is a radioactive isotope which is used to date recent sediments $(<150 \mathrm{yr})$. Here we contrast the chronologies resulting from two different ${ }^{210} \mathrm{~Pb}$ dating models: the Constant Flux model (also known as the Constant Rate of Supply model) and the recently developed Bayesian Plum model. This comparison was implemented by using four sediment cores from contrasting environmental settings, and showed several benefits of using a Bayesian approach. This allows to infer variables, such as the supported levels of ${ }^{210} \mathrm{~Pb}$, crucial to the chronology and commonly estimated through either samples where an asymptotic behaviour is observed or through ${ }^{226} \mathrm{Ra}$ measurements, which themselves contain some level of uncertainty. Another step of traditional methods is the selection of the equilibrium depth in order to calculate total inventories, which carries outstrong consequences for the resulting age depth model. Plum, on the other hand, infers the ${ }^{210} \mathrm{~Pb}$ flux, which eliminates the need to select an equilibrium depth and allows for dating cores with incomplete inventory.

31 When traditional methods address cores with missing inventory, ${ }^{137} \mathrm{Cs}$ time markers are commonly used to correct the chronology, but Plum can use these time markers to improve the chronology and to reduce the uncertainty. These aspects show that 34 the Bayesian approach results in more robust and objective chronologies, and thus 35 in better reconstructions of environmental change over the past centuries.

36 Keywords: ${ }^{210} \mathrm{~Pb}$ sediment dating, Bayesian Statistics, Uncertainty, Marine, Coast, 37 Lake. 


\section{Introduction}

39 Historical records of global change provide essential information to identify the main

40 stressors affecting ecosystems. Such environmental information can feed models of

41 potential impact scenarios and guide the development of appropriate mitigation

42 strategies. However, because long-term instrumental records are still scarce, natural

43 archives such as sediment cores from aquatic ecosystems that accumulate

44 continuously, have become one of the most relevant resources of retrospective

45 information to establish trends of environmental changes on time-scales from years

46 to millennia or more. This information, which includes rates of change, ages of

47 events and timing differences between records, should be based on reliable 48 chronologies.

${ }^{210} \mathrm{~Pb}$ is the most widely used radionuclide to date sediment records within the

50 past $110-150$ years, a period that includes the Anthropocene, with huge global

51 changes associated with the need to provide food and energy resources to a rapidly

52 growing human population (Waters et al., 2016). ${ }^{210} \mathrm{~Pb}(\mathrm{t} / 2=22.23$ years) belongs to

53 the ${ }^{238} \mathrm{U}$ natural decay series, and its abundance in sediments $\left({ }^{210} \mathrm{~Pb}\right.$ tot $)$ results from

54 the mixture of (a) supported ${ }^{210} \mathrm{~Pb}\left({ }^{210} \mathrm{~Pb}_{\text {sup }}\right)$ produced in situ through the decay of $55{ }^{226} \mathrm{Ra}$ in the lithosphere, and (b) excess ${ }^{210} \mathrm{~Pb}\left({ }^{210} \mathrm{Pbex}\right)$ produced after ${ }^{222} \mathrm{Rn}$ decay 56 and transferred to sediments through dry and wet deposition, water column 57 scavenging and runoff. Because ${ }^{210} \mathrm{~Pb}$ ex is deposited the sediment's surface and 58 decays over time, its activity decreases with increasing sediment depth in cores from 59 undisturbed sediment deposits, enabling the establishment of chronologies (Appleby 60 and Oldfield, 1992). 
The Constant Flux (CF) model, also known as the Constant Rate of Supply

62 (CRS), (Robbins, 1978; Appleby, 1978) is a robust and widely used ${ }^{210} \mathrm{~Pb}$ dating model. It is based on the fundamental equation that establishes that ${ }^{210} \mathrm{~Pb}$ ex activities depend on the ${ }^{210} \mathrm{~Pb}_{\text {ex }}$ flux to the sediment surface and the sediment mass loading (Krishnaswamy et al., 1971; Sanchez-Cabeza and Ruiz-Fernández, 2012). The main hypothesis behind the CF model is that the ${ }^{210} \mathrm{Pbex}$ flux is constant, and this can be used to infer estimates of temporal variations of sediment accumulation rates (SAR, cm year ${ }^{-1}$ ) and mass accumulation rates (MAR, $\mathrm{g} \mathrm{cm}^{-2}$ year-1). Age calculations are based on the total inventory of ${ }^{210} \mathrm{~Pb}$ ex (i.e. the accumulated deposit per unit area), which requires estimates of ${ }^{210} \mathrm{~Pb}_{\mathrm{ex}}$ data for each core section until 71 reaching the equilibrium depth (where ${ }^{210} \mathrm{~Pb}$ tot and ${ }^{210} \mathrm{~Pb}$ sup activities become 72 indistinguishable). Therefore, missing ${ }^{210} \mathrm{~Pb}$ ex data should be estimated by 73 interpolation or, in the case of cores not reaching equilibrium, missing inventory 74 extrapolated (Appleby, 2002). These restrictive requirements might cause problems 75 in sub-optimal cores (e.g., those with incomplete ${ }^{210} \mathrm{~Pb}$ ex inventory, poorly defined $76{ }^{210} \mathrm{~Pb}$ equilibrium depth, or varying ${ }^{210} \mathrm{~Pb}$ sup). Therefore, some CF-derived age77 models may not provide reliable chronologies, especially given the extensive global 78 land use changes that have taken place over the past century.

Recently, Aquino-López et al. (2018) developed a new model for ${ }^{210} \mathrm{~Pb}$ dating 80 called Plum, which is also based on the fundamental equation and the CF 81 hypothesis. Plum is a Bayesian forward model that simultaneously integrates two 82 different processes: (1) the behaviour of the ${ }^{210} \mathrm{~Pb}$ flux and the variation of ${ }^{210} \mathrm{~Pb}$ sup 83 with depth, and (2) an age-depth function (based on Bacon, a Bayesian piece-wise

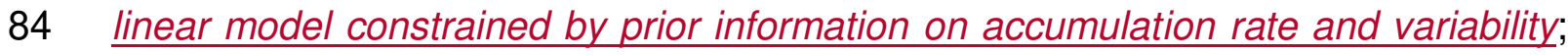


85 Blaauw and Christen 2011). These processes are parameterized, which allows the use of a Bayesian approach. With the help of millions of Monte Carlo Markov Chain 87 (MCMC) iterations, a posterior sample can be obtained. This posterior sample combines a priori information of sediment accumulation rates, ${ }^{210} \mathrm{~Pb}$ ex flux (typically observed in a given sampling site type) and data $\left({ }^{210} \mathrm{~Pb}\right.$ tot and ${ }^{226} \mathrm{Ra}$ laboratory measurements, and potentially additional information from other radioactive isotopes such as ${ }^{137} \mathrm{Cs}$ and ${ }^{14} \mathrm{C}$ ). Within any of the iterations, Plum chooses values for both the age-depth function, which assigns ages to any depth, and the ${ }^{210} \mathrm{~Pb}$ flux and ${ }^{210} \mathrm{~Pb}_{\text {sup }}$. With these parameters and the given ${ }^{210} \mathrm{~Pb}$ 's known $\mathrm{t} / 2$, values for ${ }^{210} \mathrm{~Pb}_{\text {tot }}$ can be calculated and compared to the measurements at any depth. Plum only requires experimental data on sediment density, ${ }^{210} \mathrm{~Pb}$ tot and ${ }^{226} \mathrm{Ra}$ activities (or at least a good approximation of ${ }^{210} \mathrm{~Pb}$ sup) and the outputs include estimates of ${ }^{210} \mathrm{~Pb}$ xs flux, supported ${ }^{210} \mathrm{~Pb}$ and sediment ages. Any of these parameters are expressed as posterior distributions and $95 \%$ confidence intervals.

In comparison to the traditional implementation of the CF model, which is a reverse and deterministic model (e.g. ages are directly inferred from ${ }^{210} \mathrm{~Pb}$ tot and $101{ }^{226} \mathrm{Ra}$ laboratory data), Plum is a much more flexible forward model that allows coping with non-ideal ${ }^{210} \mathrm{~Pb}$ depth profiles (variable compaction poorly-defined equilibrium depth). In addition, it can easily handle gaps in ${ }^{210} \mathrm{~Pb}$ data or multiple measurements even from the same depth, and can include other types of dating information (e.g. ${ }^{14} \mathrm{C}$ dates, ${ }^{137} \mathrm{Cs}$ peak and tephras). In this work, we present results of a test on the efficacy and reliability of the 107 CF and Plum models using data of previously published ${ }^{210} \mathrm{~Pb}$-dated sediment cores 108 from contrasting environments (deep and shallow marine areas, a crater lake, and a 
saltmarsh) where dating difficulties were encountered. Our hypothesis was that Plum

110 is better than CF in managing the assumptions involved with the ${ }^{210} \mathrm{~Pb} \mathrm{CF}$ model

111 and in estimating age uncertainties. The age models obtained were contrasted with

112 stratigraphic markers (e.g. ${ }^{137} \mathrm{Cs}$, Pu isotopes) for validation.

\section{2. Study area}

114 The sediment cores were collected from four contrasting environments in Mexico, in 115 order to reconstruct the temporal trends of a range of global change indicators 116 (Figure 1). Core IXW-500 (Ruiz-Fernández et al., 2019a) was collected from a deep117 sea area in the southern Gulf of Mexico (Atlantic Coast) characterized by strong 118 fluvial input, natural oil seeps, intense maritime traffic and offshore oil extraction 119 activities, and was used to assess trace metal contamination.

120 Core Tehua-Il (Ruiz-Fernández et al., 2009b) was sampled from a shallow 121 marine area in the Tehuantepec Gulf (Pacific Coast) characterized by high 122 productivity associated with fluvial inputs and intense upwelling, which sustains 123 relevant commercial fisheries (e.g. tuna, shrimp and shark) and experiences strong 124 shipping traffic owing to oil production and distribution activities. For this core, 125 temporal variations of sediment accumulation rates were determined in order to 126 reconstruct land use changes.

127 Core All (Ruiz-Fernández et al., 2016) was sampled to estimate rates of sea 128 level rise at a saltmarsh in Estero de Urías (Gulf of California, Pacific Coast) an 129 anthropized lagoon that hosts a harbour with shipping activities ranging from 130 cabotage and fishing (mainly tuna and shrimp) to passenger cruises, and which also 131 receives untreated domestic and industrial wastes. 
Finally, core SAMO2014-2 (Ruiz-Fernández et al., 2019b) was collected to 133 determine mass accumulation rates in Lake Santa Maria del Oro, a 2-km diameter 134 and 65m deep oligomictic and mesotrophic crater lake (Cardoso-Mohedano et al., 135 2019). The lake is mainly used for recreational activities, and it is located within the 136 Trans-Mexican Volcanic Belt at $65 \mathrm{~km}$ from the Pacific Coast.

\section{Methods}

138 The sediment cores were collected with transparent PVC tubes of different internal diameter and assisted by different types of samplers (see Table 1 for sampling details). The cores were extruded and cut into contiguous $1 \mathrm{~cm}$ thick sections.

141 Samples were weighed before and after freeze-drying; sediment bulk density $\left(\mathrm{g} \mathrm{cm}^{-}\right.$

$142{ }^{3}$ ) was calculated as the ratio of the total dry mass and the volume (from diameter 143 and thickness) of each core section.

144 3.1. Laboratory analysis

145 All sediment cores were analysed in the Sediment Dating Academic Service at 146 UNAM, following the methodology described in previous publications (Ruiz147 Fernández et al., 2009, 2016, 2019a, 2019b). To summarise, ${ }^{210} \mathrm{~Pb}$ tot activities were 148 measured using alpha spectrometry (Alpha Ensemble Ortec/Ametek) according to 149 Ruiz-Fernández and Hillaire-Marcel (2009). ${ }^{210} \mathrm{~Pb}_{\text {sup }}$ activities were estimated using 150 gamma spectrometry measurements of ${ }^{226} \mathrm{Ra}$ activities (through its daughter 151 radionuclide ${ }^{214} \mathrm{~Pb}, 352 \mathrm{keV}$ ) using a low-background Ortec HPGe well-detector 152 (Ruiz-Fernández et al., 2014). ${ }^{210} \mathrm{Pbxs}$ activities were determined using the difference 153 between ${ }^{210} \mathrm{~Pb}$ tot and ${ }^{210} \mathrm{~Pb}$ sup activities. To validate the ${ }^{210} \mathrm{~Pb}$-derived chronologies, 154 the activity profiles of ${ }^{137} \mathrm{Cs}$ against depth were determined by gamma-ray 155 spectrometry (662 keV) in all cores, and plutonium isotopes were determined by i) 
alpha-particle spectrometry for core SAMO14-2 (Ruiz-Fernández et al., 2019b), ii)

157 low-energy accelerator mass spectrometry for core EUIII (in Centro Nacional de 158 Aceleradores, Spain; Ruiz-Fernández et al., 2016) and iii) mass spectrometry in 159 Spiez Laboratory (Switzerland) for core IXW-500.

\section{2. ${ }^{210} \mathrm{~Pb}$-derived chronologies}

161 In the original papers, chronologies, mass and sediment accumulation rates were estimated with the constant flux (CF) model (Appleby and Oldfield, 1978; Robbins, 1978; Sanchez-Cabeza and Ruiz-Fernández, 2012). Dating uncertainties in core Tehua-II were calculated using quadratic propagation uncertainty, whereas in the other cores they were estimated by Monte Carlo simulation with $10^{5}$ simulations (Sanchez-Cabeza et al., 2014).

The Plum age-depth models were obtained using the default settings. These 168 settings dictate the prior distributions used for the supported ${ }^{210} \mathrm{~Pb},{ }^{210} \mathrm{~Pb}$ flux, and 169 sedimentation rate and its variability (used within each Bacon section), as well as 170 the thickness of Bacon sections. By default, Plum uses 1-cm thick Bacon sections 171 (whereas Bacon's default is 5, which is probably too restrictive to model 172 sedimentation close to the surface). The default prior distribution for the supported $173{ }^{210} \mathrm{~Pb}$ parameters is a gamma distribution with a mean of $15 \mathrm{~Bq} \mathrm{~kg}^{-1}$ and a shape 174 parameter of 2 . For core IXW500, Plum used the ${ }^{226}$ Ra measurements to obtain 175 estimates for supported ${ }^{210} \mathrm{~Pb}$ at multiple depths, whereas for the other cores 176 supported ${ }^{210} \mathrm{~Pb}$ was assumed to be constant throughout each core. For the ${ }^{210} \mathrm{~Pb}$

177 flux, Plum uses a gamma distribution with a mean of $50 \mathrm{~Bq} \mathrm{~m}^{-2} \mathrm{yr}^{-1}$ and a shape 178 parameter of 2. Plum also uses an upper age limit, for which it uses a parameter set 179 to $A_{l}=0.1$ by default, which is defined as the remaining unmeasured ${ }^{210} \mathrm{~Pb}$ ex. This 
180

181 according to the inferred ${ }^{210} \mathrm{Pbex}$ flux. Plum also can use information from time-

markers such as the human-made peak in ${ }^{137} \mathrm{Cs}$ to refine the age-depth model, but 183 this was ignored as we wanted to observe only the behaviour of the ${ }^{210} \mathrm{~Pb}$ data on 184 their own.

\section{Results}

Figures 2, 3, 4 and 5 show the comparisons between the ${ }^{210} \mathrm{~Pb}$-derived chronologies using the CF and Plum dating models.

\subsection{TEHUA-II}

189 In the case of TEHUA-II (Figure 2), both models agreed well with each other 190 throughout the chronologies. The CF confidence intervals overlapped Plum's 191 credible intervals, i.e. Plum provided narrower intervals. In this case, Plum was able 192 to extend the chronology by up to two decades, because fewer measurements were 193 discarded in order to infer the supported ${ }^{210} \mathrm{~Pb}$. Both models agreed quite well with 194 the 1963 time-marker.

195 4.2. $E U-I I I$

196 Figure 3 shows the comparison between the CF and Plum age-models of core EU197 III. In this case, the chronologies agreed well with each other, providing similar age 198 estimates and similar credible and confidence intervals. Again, Plum was able to 199 extend the chronology for several decades as several more data points are used to 200 infer the chronology: CF inferred a chronology up to a depth of $27.5 \mathrm{~cm}$, whereas 201 Plum reached a depth of $39 \mathrm{~cm}$. Regarding the 1963 time marker, Plum seems to 202 agree better as the CF model provided younger ages and its uncertainty was 203 insufficient to enclose the time marker. 
205 SAMO14-2's chronology (Figure 4) showed that the age estimates are in good 206 agreement and both models enclose the time marker within its intervals. On the other 207 hand, the model's uncertainty estimates show largeed differences, with Plum 208 providing more conservative uncertainty estimates. Regarding the length of the 209 chronology, Plum was again able to extend the chronology by several decades by 210 its use of fewer measurements to infer the supported ${ }^{210} \mathrm{~Pb}$ value.

\section{4.4. IXW-500}

212 In this case, the CF- and Plum- derived age models resulted in significant differences 213 (Fig. 5) at different core depths. In comparison with CF ages, Plum ages were older 214 in the segments surface $-4 \mathrm{~cm}$ and $8-12 \mathrm{~cm}$, but comparable within the segments $2155-8 \mathrm{~cm}$ and below $12 \mathrm{~cm}$. Plum provided a more conservative age estimate, with 216 larger and more credible intervals than the CF model. In this particular case, The 217 Plum-derived age model comprised almost twice the CF age period (age estimate 218 of 160 years at $15 \mathrm{~cm}$ depth and 308 years at $29 \mathrm{~cm}$ depth). This was caused by CF 219 having to discard the 5 bottom measurements, whereas Plum was able to extract 220 information from them.

The considerable differences between the models could be caused by the peculiar ${ }^{226}$ Ra profile of this core (shown as blue dots in the supported ${ }^{210} \mathrm{~Pb}$ panel in Figure 4). The largest difference between the age models was observed at mid-

224 depth, where a minimum ${ }^{210} \mathrm{Pbex}$ in activity occurs, caused by large ${ }^{226} \mathrm{Ra}$ activity. 225 This also resulted in both models presenting a change in behaviour at this depth, 226 with a larger accumulation rate at depths lower than $9 \mathrm{~cm}$. In this case, refining the 227 chronology using more information (e.g. ${ }^{137} \mathrm{Cs}$ ) could be of help, as Plum can include 
228 these time markers to the likelihood function in order to obtain an integrated 229 chronology.

230 It is important to note that both total ${ }^{210} \mathrm{~Pb}$ and ${ }^{226} \mathrm{Ra}$ at the five deepest samples 231 were very similar, i.e. equilibrium was reached. In this case, Plum uses the 232 information provided by the rest of the core and the prior distribution to provide an 233 informed extrapolation.

\section{5. Discussion}

\subsection{Tehua-II and EU-III}

As all sections of these cores were measured down to equilibrium, as expected both 237 models provided similar results. In the case of TEHUA-II, Plum provided narrower 238 credible intervals, which are a result of the use of the Bacon age-depth function, 239 instead of the decay equation used by the CF model. On the other hand, the age240 models for EU-III agreed well and reconstructed similar uncertainty intervals. Plum 241 was able to extend the chronology by a couple of decades in the case of TEHUAll 242 and by more than $100 \mathrm{yr}$ in the case of EU-III. This is a result of Plum's integration 243 of supported ${ }^{210} \mathrm{~Pb}$ in the inference process, removing the need to discard the 244 lowermost few measurements.

245 5.2. SAMO14-2

246 SAMO14-2 presents an interesting case as relatively few data points were available

247 for the inference. Both models presented overlapping results. In this case, Plum 248 provided wider intervals as a result of the low number of samples measured for this 249 core. The CF model provided very precise age estimates, apparently a positive 250 outcome, but considering that less than $25 \%$ of the core sections were measured 251 (10 measurements of $1 \mathrm{~cm}$ sections were used to infer the chronology to a depth of 
$25241 \mathrm{~cm}$ ), the more conservative intervals provided by Plum are more coherent. This

253 is an important consequence of the interpolations used to estimate the ${ }^{210} \mathrm{~Pb}_{\mathrm{ex}}$ 254 inventories, which do not consider the error caused by the absence of 255 measurements. Interestingly, something similar appears to happen in simulated and 256 real-world ${ }^{14} \mathrm{C}$-dated cores modelled using classical and Bayesian age-models 257 (Blaauw et al. 2018): whereas Bayesian age-models become more precise with 258 increasing dating densities (they 'learn'), classical age-models such as linear 259 interpolation do not.

260 5.3. $I X W-500$

261 This core presented significant differences between each model. Plum inferred lower 262 levels of supported ${ }^{210} \mathrm{~Pb}$ at $8-10 \mathrm{~cm}$ depths in comparison to the measured ${ }^{226} \mathrm{Ra}$ 263 (see Figure 5). It is at these depths where both models show their largest 264 discrepancies. In this case, more measurements around the spike of ${ }^{226} \mathrm{Ra}$ could 265 help Plum to model these unusual spikes. Also, Plum can use other time markers 266 such as ${ }^{137} \mathrm{Cs}$ to refine the chronology.

267 5.4. Plum extended chronologies

268 As shown, Plum is able to obtain longer chronologies. In some cases, the extension 269 is a result of fewer samples being used exclusively to infer supported ${ }^{210} \mathrm{~Pb}$ and/or 270 the use of the final sample with ${ }^{210} \mathrm{~Pb}_{\mathrm{ex}}$ not being discarded (which is common 271 practice when using the CF model). These extensions provide an accurate 272 chronology with an uncertainty similar to the rest of the chronology. In other cases, 273 like IXW-500, it is the result of using ${ }^{226} \mathrm{Ra}$ concentrations combined with a sediment 274 with ${ }^{210} \mathrm{~Pb}$ in equilibrium. Plum provides a much larger extension in these 275 chronologies, but this should be taken with extra caution, since at depths below 
where ${ }^{210} \mathrm{~Pb}$ ex is available, age uncertainties become considerably higher and precision decreases. These extensions are a linear simplification, which uses information from both the data and the prior distributions for the accumulation rate and variability. Under simulation, we have observed that these extensions become more inaccurate with depth, but the credible intervals (larger than in the rest of the

281 chronology) are able to capture the true age. These extensions are rather qualitative and should not be used to obtain conclusions on sedimentary processes and 283 records. Because simulations are not within the scope of the present study, these 284 are left for future research.

285 As shown, Plum is able to obtain longer chronologies. In some cases, the extension 286 is a result of fewer samples being used exclusively to infer supported 210Pb and/or 287 the use of the final sample with 210Pbex not being discarded (which is common 288 practice when using the CF model). These extensions provide an accurate chronology with an uncertainty similar to the rest of the chronology. In other cases, like IXW-500, it is the result of using $226 \mathrm{Ra}$ concentrations combined with a sediment with 210Pb in equilibrium. Plum provides a much larger extension in these chronologies, but this should be taken with caution. These extensions are a linear simplification, which uses information from both data and the prior distribution for the accumulation rate. Under simulation, we have observed that these extensions become more inaccurate with depth, but the credible intervals (larger than in the rest of the chronology) are able to capture the true age. These extensions are rather qualitative and should not be used to obtain conclusions on sedimentary processes 298 and records 


\subsection{CF rapid accumulation}

300 The CF model was constructed using the decay equation as its basis, which resulted

301 in a logarithmic age-depth function; $t(x)=\lambda^{-1} \log \left(\frac{A(0)}{A(x)}\right)$. This age-depth function 302 works well in the most recent part of the sediment, but as the remaining activity $A(x)$ 303 gets close to 0 , the age function rapidly tends to infinity, resulting in an artificial 304 increase of accumulation rates. This increase is not caused by natural sources but 305 it is a result of the mathematical structure of the model and should not be included 306 in interpretations. On the other hand, because Plum uses an independent age-depth 307 function, it does not show this artificial increase in accumulation, providing a more 308 realistic age-depth function at deeper parts of the sediment.

309 5.6. Overall considerations

310 When CF model users are confronted with a new core, a number of decisions must 311 be made based on the available information. Because of resource constraints, 312 typically not all core sections are measured and interpolation techniques are needed, 313 which may induce an experimental error. By design, Plum does not need any kind 314 of interpolation and solely relies on the existing data. While both the CF model and 315 Plum should produce better age-models with more data (i.e. more information), Plum 316 results are undoubtedly more reliable when some data are missing.

317 The reliability of measurement can also be sometimes an issue. For example, 318 the CF radiochronologist might decide that a measurement is an outlier, or that 319 concentrations close or below $0 \mathrm{~Bq} \mathrm{~kg}^{-1}$ are zero. In the case of Plum, this is not an 320 issue, as the system will choose, based on Bayesian statistics, which is the best set 
321 of activities and, in some cases, disregard an outlier or ignore low (or negative) 322 concentrations, without human intervention.

323 One of the critical decisions that must be taken when using the CF model is 324 the selection of the equilibrium depth of the core, i.e., the depth where the ${ }^{210} \mathrm{~Pb}_{\mathrm{ex}}$ 325 reaches zero and from where the total ${ }^{210} \mathrm{~Pb}$ ex inventory can be calculated. The 326 equilibrium depth mainly depends on the unambiguous knowledge of the ${ }^{210} \mathrm{~Pb}$ sup 327 value. This is often difficult to ascertain owing to i) large relative uncertainties of $328{ }^{210} \mathrm{~Pb}$ ex, when calculated by subtraction of ${ }^{210} \mathrm{~Pb}$ and ${ }^{226} \mathrm{Ra}$ (or an estimated ${ }^{210} \mathrm{~Pb}$ sup), 329 which can be very similar at the core bottom, and ii) changes in sediment 330 composition which can produce variations of ${ }^{210} \mathrm{~Pb}_{\text {sup }}$ activities along a core (e.g. 331 Carnero-Bravo et al. 2016), which will affect the total ${ }^{210} \mathrm{~Pb}_{\mathrm{xs}}$ inventory and thus the 332 core age, as higher inventories will cause younger ages and vice versa. Therefore, 333 depending on the core's ${ }^{210} \mathrm{~Pb}$ activity profile, small variations of specific activities 334 could produce age variations amounting to decades. A relevant feature of Plum is \$35 that ${ }^{210} \mathrm{~Pb}_{\text {sup }}$ is not a a value to be provided by the user user's input-but a parameter 336 to be inferred. Plum uses data to infer ${ }^{210} \mathrm{~Pb}_{\text {sup, }}$ which can be ${ }^{226} \mathrm{Ra}$ measurements 337 or ${ }^{210} \mathrm{~Pb}$ which reached equilibrium. If only ${ }^{210} \mathrm{~Pb}$ is available, Plum runs a pre338 analysis based on a linear regression, where the segment which provides the largest 339 p-value (and thus lower variability) is suggested to be used exclusively to infer $340{ }^{210} \mathrm{~Pb}_{\text {sup. }}$. Because the $\mathrm{p}$-value is affected by sample size, this pre-analysis should be 341 confirmed by the user, but it has provided reasonable results in several simulations 342 and real cores. This reduces considerably the calculation efforts and decisions of the 343 user, and maximizes the confidence in the ${ }^{210} \mathrm{~Pb}$ sup value. 
Sometimes the ${ }^{210} \mathrm{~Pb}$ profile is incomplete, i.e. ${ }^{210} \mathrm{~Pb}$ does not reach

345 equilibrium. In this case, CF users need to estimate the missing inventory from either

346 a bottom constant accumulation rate, or by using a reference date (e.g. the ${ }^{137} \mathrm{Cs}$ 347 maximum). In the case of Plum this is not needed, as even in these cases Plum will 348 estimate the total ${ }^{210} \mathrm{Pbex}$ flux by Bayesian statistics.

In overall, these and other decisions may cause different scientists, or even the same scientist at different moments, to produce different chronologies with the same data set and using the same model. As Plum uses existing information, age models should be identical (as long as the prior parameters are the same) and the user-based bias should largely reduced. In this sense, Plum is clearly more objective and we suggest that it should be widely used by ${ }^{210} \mathrm{~Pb}$ radiochronologists. Plum produces ${ }^{210} \mathrm{~Pb}$-chronologies up the maximum core length (Fig. 5) based on the assumption that mass accumulation rates $\left(\mathrm{gcm}^{-2}-\mathrm{yr}^{-1}\right)$ are constant beyond the core section from where ${ }^{210} \mathrm{~Pb}_{\text {ex }}$ is available and using both data from the most recent part of the sediment and the prior distribution. This is a useful Plum feature allowing practical applications (e.g. selection of core sections from preindustrial times, a rough estimation of the maximum core age, correlation among core sections). However, caution is advised when using these extrapolated ages beyond where ${ }^{210} \mathrm{~Pb}$ ex is available, since age uncertainties become considerably higher and precision decreases. The behaviour of these extensions can only be analysed with help of simulations. Because simulations are not within the scope of this study, these are left for a future study.

In this comparison study, only ${ }^{210} \mathrm{~Pb}$ measurements were used to produce 367 chronologies. However, for core IXW-500 additional nuclides were measured, 
368 including ${ }^{137} \mathrm{Cs}$, which has known historical peaks caused by radioactive releases

369 into the atmosphere. Such peaks are regularly used to validate or adjust ${ }^{210} \mathrm{~Pb}$-based

370 chronologies. Plum can integrate such information, as well as ${ }^{14} \mathrm{C}$ and other dates,

371 into the ${ }^{210} \mathrm{~Pb}$ chronology.

372 6. Conclusions

373 The application of the CF ${ }^{210} \mathrm{~Pb}$ sediment dating model requires from the 374 radiochronologist several inputs, such as the equilibrium depth and data 375 interpolation when not all sections are measured, a rather common case. However, 376 with the Bayesian approach used by Plum this is no longer needed, thus making the 377 dating process less subjective and more reproducible.

378 The comparison of both approaches show that Plum provides similar results 379 to the classical CF model, with the added benefits of providing more precise 380 uncertainty estimates when sampling density is high (like in the case of TEHUA-II 381 and EU-III), and providing more realistic uncertainty estimates where few samples 382 are available (SAMO14-2). Also, Plum is not affected by artificial increases of 383 sedimentation in the deepest part of the sediment, unlike the CF model where the 384 logarithmic age-function tends to infinity as background is reached. This allows the 385 user to interpret dates deeper in the core without being affected by artificial increases \$86 in the sedimentation.

Plum' older ages, obtained by the usability of more data, appears to be in

disagreement with previous chronology limits (Appleby, 1998). This point was

previously addressed by Aquino-López el at. (2018), as by using simulations it was

shown that these older ages remained accurate when the core is fully sampled.

These older ages are also accompanied by a more realistic uncertainty (much larger 
credible intervals), and should be handled with caution, even more when the core was-is not fully sampled. Users and/or studies which required less uncertainty should $\underline{\text { consider discarding these older ages or providing the model with other time markers, }}$ which will improve the levels of uncertainty and help the model provide a more

\section{precise chronology.}

The ability of adding extra information such as ${ }^{137} \mathrm{Cs}$, radiocarbon dates and/or tephra dates can be used for both validating the chronology or improving it. Because Plum uses raw ${ }^{210} \mathrm{~Pb}$ to create the chronology, multiple isotope chronologies are possible without having to pre-model the ${ }^{210} \mathrm{~Pb}$ dates. This quality should not be underestimated, as the effects of the bias in the deepest part of the sediment presented by the CF model have not yet been studied. Because of all these considerations, we believe that Plum has the potential of providing more robust and objective ${ }^{210} \mathrm{~Pb}$ chronologies.

\section{Acknowledgements}

The authors acknowledge partial financial support from a Royal Society-Newton Mobility Grant (Dating the decadal-scale dynamics of ENSO and pollution trends from crater lake sediments in Nayarit, western tropical Mexico), CONACYT (PDCPN 2015-01/473, CONACYT-CNR C0013-2016-05-277942, SEMARNAT-2016-01278634), UNAM (PAPIIT IN110518 and IN104718; LANCAD-UNAM-DGTIC-273). Part of this work was funded by a CONACYT postgraduate scholarship 411036 to Marco A. Aquino-López at Queen's University Belfast. Authors are grateful to the technical support received by L.H. Pérez-Bernal, León Felipe Álvarez, H. BojórquezLeyva, S. Rendón-Rodríguez, G. Ramírez Reséndiz and C. Suárez-Gutiérrez.

\section{Data Availability}


416 Sediment data are available as supplementary material.

417 Supplementary material

- Data used for ${ }^{210} \mathrm{~Pb}$ dating with Plum.

References

420

Appleby, P. G., Oldfield, F. (1978). The calculation of lead-210 dates assuming a constant rate of supply of unsupported ${ }^{210} \mathrm{~Pb}$ to the sediment. Catena, $5(1), 1$ 8.

Appleby, P. G., Oldfield, F. (1992). Application of lead-210 to sedimentation studies. Uranium-Series Disequilibrium: Applications to Earth, Marine, and Environmental Sciences, 2nd edition. Oxford: Clarendon, 731-778.

Appleby, P. G. (1998). Dating recent sediments by 210Pb: Problems and solutions. Proc. 2nd NKS/EKO-1 Seminar, Helsinki, 2-4 April 1997, STUK, Helsinki, pages 7-24.

Appleby, P. G. (2002). Chronostratigraphic techniques in recent sediments. In Tracking environmental change using lake sediments (pp. 171-203). Springer, Dordrecht.

Aquino-López, M. A., Blaauw, M., Christen, J. A., Sanderson, N. K. (2018). Bayesian analysis of ${ }^{210} \mathrm{~Pb}$ dating. Journal of Agricultural, Biological and Environmental Statistics, 23(3), 317-333.

Blaauw, M. Christen, J. A. (2011). Flexible paleoclimate age-depth models using an autoregressive gamma process. Bayesian Analysis, 6(3), 457-474.

Blaauw, M., Christen, J.A., Bennett, K.D., Reimer, P.J., 2018. Double the dates and go for Bayes - impacts of model choice, dating density and quality on chronologies. Quaternary Science Reviews, 188, 58-66 
440 Cardoso-Mohedano, J. G., Sanchez-Cabeza, J. A., Ruiz-Fernández, A. C., Pérez441 Bernal, L. H., Lima-Rego, J., Giralt, S. (2019). Fast deep water warming of a subtropical crater lake. Science of the Total Environment, 691, 1353-1361.

443 Carnero-Bravo, V., Sanchez-Cabeza, J. A., Ruiz-Fernández, A. C., Merino-Ibarra, M., Hillaire-Marcel, C., Corcho-Alvarado, J. A., Röllin, S., Diaz-Asencio, M., Cardoso-Mohedano, J.G., \& Zavala-Hidalgo, J. (2016). Sedimentary records of recent sea level rise and acceleration in the Yucatan Peninsula. Science of the Total Environment, 573, 1063-1069.

Krishnaswamy, S., Lal, D., Martin, J., Meybeck, M. (1971). Geochronology of Lake Sediments. Earth and Planetary Science Letters 11: 407-14.

Robbins J. A. (1978) Geochemical and geophysical applications of radioactive lead isotopes. In Biochemistry of Lead (ed. J. O. Nriagu). Elsevier, Amsterdam, pp. 85-393.

Ruiz-Fernández A.C., Hillaire-Marcel C. (2009a). ${ }^{210} \mathrm{~Pb}$-derived ages for the 454 reconstruction of terrestrial contaminant history into the Mexican Pacific coast: Potential and limitations. Marine Pollution Bulletin 59, 134-145.

Ruiz-Fernández A. C., Hillaire-Marcel C., de Vernal A., Machain-Castillo M. L., Vásquez L., Ghaleb B., Aspiazu-Fabián, J.A., Páez-Osuna F. (2009b). Changes of coastal sedimentation in the Gulf of Tehuantepec, South Pacific Mexico, over the last 100 years from short-lived radionuclide measurements.

461 Ruiz-Fernández, A. C., Maanan, M., Sanchez-Cabeza, J. A., Pérez-Bernal, L. H., 462 López-Mendoza, P., Limoges, A. (2014). Chronology of recent sedimentation 
and geochemical characteristics of sediments in Alvarado Lagoon, Veracruz (southwestern gulf of Mexico). Ciencias Marinas, 40(4), 291-303.

Ruiz-Fernández A. C., Sanchez-Cabeza J. A., Serrato de la Peña J. L., Perez-Bernal L. H., Cearreta, A., Flores-Verdugo F., M. L. Machain-Castillo, Chamizo E., García-Tenorio R., Queralt I., Dunbar R. B., Mucciarone D.A., Diaz-Asencio M. (2016). Accretion rates in coastal wetlands of the southeastern Gulf of California and their relationship with sea level rise. The Holocene 26, 7, 11261137.

Ruiz-Fernández A.C., Sanchez-Cabeza J.A., Pérez-Bernal L. H., Gracia-Gasca A. (2019a). Spatial and temporal distribution of heavy metal concentrations and enrichment in the Southern Gulf of Mexico. The Science of the Total Environment 651, Part 2, 3174-3186.

Ruiz-Fernández A.C., Sanchez-Cabeza J. A., Hernández-Rivera D.M., Pérez-Bernal L. H., Cardoso-Mohedano J. G. (2019b). Historical reconstruction of sediment accumulation rates as an indicator of global change impacts in a tropical crater lake in Mexico. In preparation.

479 Sanchez-Cabeza J.A., Ruiz-Fernández A.C. (2012). ${ }^{210} \mathrm{~Pb}$ sediment radiochronology: an integrated formulation and classification of dating models. Geochimica et Cosmochimica Acta 82, 183-200. LH, Olid C (2014). Monte Carlo uncertainty calculation of ${ }^{210} \mathrm{~Pb}$ chronologies and accumulation rates of sediments and peat bogs. Quaternary Geochronology 23, 80-93 
486 Waters, C. N., Zalasiewicz, J., Summerhayes, C., Barnosky, A. D., Poirier, C., 487 Gałuszka, A., Cearreta, A., Edgeworth, M., Ellis, E.C., Ellis, M., Jeandel, C., 488 Leinfelder, R., McNeill, J. R., Richter, D. B., Steffen, W., Syvitski, J., Vidas, D., 489 Wagreich, M., Williams, M., Zhisheng, A., Grinevald, J., Odada, E., Oreskes, 490 N., Wolfe A.P. (2016). The Anthropocene is functionally and stratigraphically 491 distinct from the Holocene. Science, 351(6269), aad2622.

492 


\section{Figure captions}

494 Figure 1. Geographical locations where sediment cores were collected.

495 Figure 2. Plum and CF age-depth models for TEHUA-II. Plum 95\% credible intervals 496 and mean are shown as red dashed lines, and dark shadow show some iterative 497 chronologies obtained by the MCMC. The CF age-depth model is shown in blue, 498 using linear interpolation between neighbouring data points used to construct the 499 model. Bottom boxes show depths where samples were analyzed. The orange box 500 shows the ${ }^{137} \mathrm{Cs} 1963$ time marker.

501 Figure 3. Plum and CF age-depth models for core EU-III. For explanation of symbols 502 and colours, see Fig. 2.

503 Figure 4. Plum and CF age-depth models for SAMO14-2. For explanation of 504 symbols and colours, see Fig. 2.

505 Figure 5. Plum and CF age-depth models for core IXW-500. For explanation of 506 symbols and colours, see Fig. 2. In the "Supported ${ }^{210} \mathrm{~Pb}$ " upper panel, black dots 507 represent Plum simulations, blue dots are the mean of the simulated values and red 508 dots are the ${ }^{226}$ Ra measurements 
510 Table 1. Sampling information for sediment cores from Mexican marine and 511 lacustrine areas.

\begin{tabular}{|c|c|c|c|c|c|}
\hline Core ID & Coordinates & $\begin{array}{l}\text { Sampling date } \\
\text { and depth }(\mathrm{m})\end{array}$ & $\begin{array}{l}\text { Length } \\
(\mathrm{cm})\end{array}$ & $\begin{array}{l}\text { Sediment } \\
\text { characteristics }\end{array}$ & $\begin{array}{l}\text { Corer type } \\
\text { and internal } \\
\text { diameter } \\
(\mathrm{cm})\end{array}$ \\
\hline IXW-500 & $\begin{array}{l}19^{\circ} 26.649^{\prime} \mathrm{N} \\
93^{\circ} 53.323^{\prime} \mathrm{W}\end{array}$ & $\begin{array}{l}06 / 08 / 2015 \\
1010\end{array}$ & 25 & $\begin{array}{l}\text { Marine muddy } \\
>94 \% \text { silt + clay }\end{array}$ & $\begin{array}{l}\text { Multicorer } \\
9.5\end{array}$ \\
\hline TEHUA-II ${ }^{\mathrm{b}}$ & $\begin{array}{l}15^{\circ} 59.987^{\prime} \mathrm{N} \\
94^{\circ} 48.469^{\prime} \mathrm{W}\end{array}$ & $\begin{array}{l}15 / 10 / 2004 \\
67\end{array}$ & 18 & $\begin{array}{l}\text { Marine sandy } \\
>75 \% \text { sand }\end{array}$ & $\begin{array}{l}\text { Reineck } \\
7\end{array}$ \\
\hline EU-IIIC & $\begin{array}{l}23^{\circ} 09.322^{\prime} \mathrm{N} \\
106^{\circ} 19.672^{\prime} \mathrm{W}\end{array}$ & $\begin{array}{l}05 / 05 / 2012 \\
0\end{array}$ & 50 & $\begin{array}{l}\text { Coastal hypersaline } \\
>60 \% \text { silt }\end{array}$ & $\begin{array}{l}\text { Push core } \\
10\end{array}$ \\
\hline SAMO14-2 ${ }^{d}$ & $\begin{array}{l}21^{\circ} 22.187^{\prime} \mathrm{N} \\
104^{\circ} 34.335^{\prime} \mathrm{W}\end{array}$ & $\begin{array}{l}28 / 04 / 2019 \\
48\end{array}$ & 78 & $\begin{array}{l}\text { Lacustrine } \\
\text { > } 80 \% \text { silt }\end{array}$ & $\begin{array}{l}\text { Uwitec }^{\mathrm{TM}} \\
8.6\end{array}$ \\
\hline
\end{tabular}

512 aRuiz-Fernández et al., 2019a; ${ }^{b}$ Ruiz-Fernández et al., 2009b, ' Ruiz-Fernandez et 513 al., 2016; dRuiz-Fernandez et al., 2019b.

514 


\section{Comparing classical and Bayesian ${ }^{210} \mathrm{~Pb}$ dating models in human-impacted aquatic environments \\ Marco A. Aquino-López, Ana Carolina Ruiz-Fernández, Maarten Blaauw, Joan-Albert Sanchez-Cabeza*}

\section{Answers to reviewers}

Dear Editor,

We thank you for your support to revise our manuscript, and thank the reviewers for their efforts in reviewing this manuscript.

We have addressed each issue mentioned by the reviewers, provide an answer in this document, and the manuscript changes are shown in track mode. We have also used the opportunity to make some minor editorial changes.

We sincerely hope that the manuscript is now acceptable for publication.

Best regards,

Prof. J.A. Sanchez-Cabeza

UNAM 
Reviewer \#1

As the time interval covered by the $\mathrm{Pb}-210$ lasts only 100 years, any extrapolation beyond this range is quite speculative. Despite the warnings in the present manuscript, it is quite dangerous to propose, as valid ages, extrapolations down to 300-400 years. Even applying C14 ages together, it will be difficult to validate this extrapolation, because of the marine reservoir effect. Therefore, I would like to propose to restrict ages not older than 150 years.

This point was addressed in the original paper (Aquino-López et al. 2018). In the section named Chronology Limit, the use of a dynamic age limit was discussed, which takes into consideration not only a single value like the one presented by Appleby (1998), or alternative values such as 100 or 150 yr. Aquino-López et al. (2018) presented a series of simulated data where we know the true age values, and this allows us to observe the accuracy of the model. These simulations show that the model does not loose accuracy even in older ages, even though error estimates become larger. Users which are uncomfortable with large uncertainties can decide to discard portions of the age-depth model, but we feel this should be left to user discretion and to the levels of uncertainty relevant to each study.

In fact, the authors of this manuscript are in debate about the validity of extensions of several decades up to centuries. Further research based on simulations is planned to properly test this important issue. However, this is outside of the scope of the current manuscript, and we have clarified this in the revised version.

In order to clarify the issue and focus the reader interest, we have summarized sub-section 5.4 Plum extended chronologies and the second last paragraph of the discussion section as:

\subsection{Plum extended chronologies}

As shown, Plum is able to obtain longer chronologies. In some cases, the extension is a result of fewer samples being used exclusively to infer supported ${ }^{210} \mathrm{~Pb}$ and/or the use of the final sample with ${ }^{210} \mathrm{~Pb}_{\text {ex }}$ not being discarded (which is common practice when using the CF model). These extensions provide an accurate chronology with an uncertainty similar to the rest of the chronology. In other cases, like IXW-500, it is the result of using ${ }^{226} \mathrm{Ra}$ concentrations combined with a sediment with ${ }^{210} \mathrm{~Pb}$ in equilibrium. Plum provides a much larger extension in these chronologies, but this should be taken with extra caution, since at depths below where ${ }^{210} \mathrm{~Pb}$ ex is available, age uncertainties become considerably higher and precision decreases. These extensions are a linear simplification, which uses information from both the data and the prior distributions for the accumulation rate and variability. Under simulation, we have observed that these extensions become more inaccurate with depth, but the credible intervals (larger than in the rest of the chronology) are able to capture the true age. These extensions are rather qualitative and should not be used to obtain conclusions on sedimentary processes and records. Because simulations are not within the scope of the present study, these are left for future research. 
Also, we have included a paragraph in the Conclusions section:

Plum' older ages, obtained by the usability of more data, appears to be in disagreement with previous chronology limits (Appleby, 1998). This point was previously addressed by Aquino-López el at. (2018), as by using simulations it was shown that these older ages remained accurate when the core is fully sampled. These older ages are also accompanied by a more realistic uncertainty (much larger credible intervals), and should be handled with caution, even more when the core was not fully sampled. Users and/or studies which require less uncertainty should consider discarding these older ages or providing the model with other time markers, which will improve the levels of uncertainty and help the model provide a more precise chronology.

Note that not all C-14 dates in the case studies were from marine sites. 
This publication is an example of the use of the new Bayesian PLUM model to date sedimentary boreholes using lead-210 measurements. It perfectly illustrates the interest of this model compared to more classical models (here the CRS model).

I would have liked an example of the Bayesian approach also using artificial radionuclides to see the complete interest of the model as well as to understand the integration of additional proxy in PLUM. In the end, is the approach completely independent of the model user or does the user tune the model in the same way as Bacon. In this case, the most important thing is that the users of the lead-210 data clearly explain their assumptions, basic data etc. (Mustaphi et al. 2019). This work deserves prompt publication.

Many thanks to the reviewer for the positive comments. We decided to not incorporate data points of artificial radionuclides into the Plum age-models, so as to provide fair comparisons with the CRS model which uses such time markers as validation only. The manuscript states: "Plum also can use information from time-markers such as the human-made peak in ${ }^{137} \mathrm{Cs}$ to refine the age-depth model, but this was ignored as we wanted to observe only the behaviour of the ${ }^{210} \mathrm{~Pb}$ data on their own." The incorporation of other dating techniques is left to future studies where we will discuss the effect and benefits this additional information has on the resulting chronology.

As for the comment on 'tuning': Plum, like Bacon, is a Bayesian approach that uses prior distributions to reconstruct the age-depth relationship. Although the default settings have been set to allow for a wide variety of sites to be age-modelled, for some cores these values need to be modified. We believe that no approach can produce entirely automated agemodels without any user input. If so desired however, the approach could be modified by replacing the Bacon component by, say, BChron which has fewer user-provided settings.

Minor comments:

\section{83 explain BACON acronym}

Bacon is not an acronym, but we have now clarified the model:

... (based on Bacon, a Bayesian piece-wise linear model constrained by prior information on accumulation rate and variability; Blaauw and Christen 2011).

I.316: user's input: please rephrase.

Rephrased to "... is not a value to be provided by the user but..." 

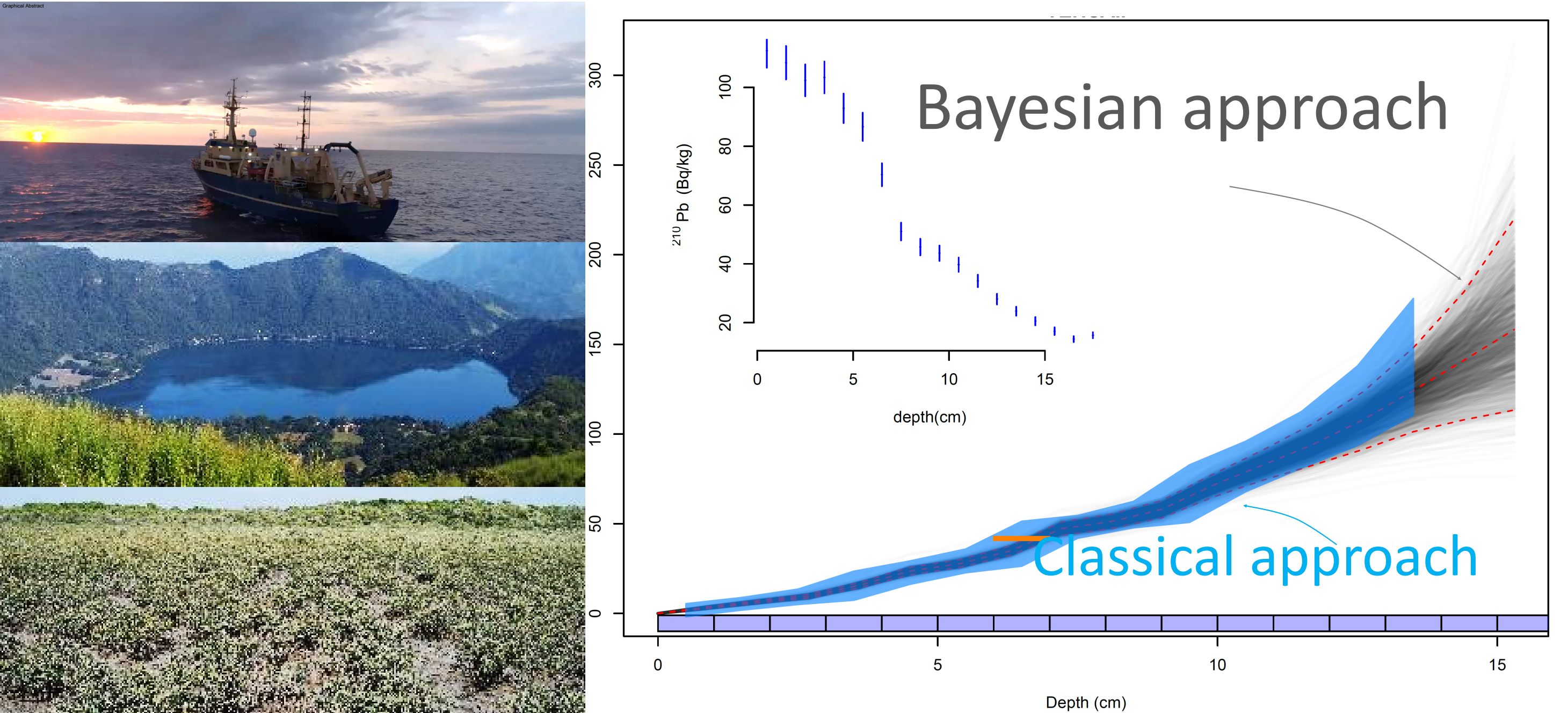


\section{Comparing classical and Bayesian ${ }^{210} \mathrm{~Pb}$ dating models in human-}

2 impacted aquatic environments

3

4 Marco A. Aquino-López ${ }^{1}$, Ana Carolina Ruiz-Fernández², Maarten Blaauw³ , Joan-

5 Albert Sanchez-Cabeza ${ }^{2 *}$

6

$7 \quad{ }^{1}$ Maynooth University, Arts and Humanities Institute, Maynooth, Co. Kildare, Ireland.

$8{ }^{2}$ Unidad Académica Mazatlán, Instituto de Ciencias del Mar y Limnología, Universidad

9 Nacional Autónoma de México, 82040 Mazatlán, México

$10{ }^{3}$ School of Natural and Built Environment, Queen's University Belfast, Belfast, UK.

11

12 *Corresponding author: jasanchez@cmarl.unam.mx

13 


\section{Abstract}

15 Chronologies are an essential tool to place natural archives of environmental changes on a calendar scale. Because of this, studies that compare and assess the accuracy and precision of available dating models are essential. ${ }^{210} \mathrm{~Pb}$ is a radioactive isotope which is used to date recent sediments $(<150 \mathrm{yr})$. Here we contrast the chronologies resulting from two different ${ }^{210} \mathrm{~Pb}$ dating models: the Constant Flux model (also known as the Constant Rate of Supply model) and the recently developed Bayesian Plum model. This comparison was implemented by using four sediment cores from contrasting environmental settings, and showed several benefits of using a Bayesian approach. This allows to infer variables, such as the supported levels of ${ }^{210} \mathrm{~Pb}$, crucial to the chronology and commonly estimated through either samples where an asymptotic behaviour is observed or through ${ }^{226} \mathrm{Ra}$ measurements, which themselves contain some level of uncertainty. Another step of traditional methods is the selection of the equilibrium depth in order to calculate total inventories, which carries strong consequences for the resulting age depth model. Plum, on the other hand, infers the ${ }^{210} \mathrm{~Pb}$ flux, which eliminates the need to select an equilibrium depth and allows for dating cores with incomplete inventory.

31 When traditional methods address cores with missing inventory, ${ }^{137} \mathrm{Cs}$ time markers are commonly used to correct the chronology, but Plum can use these time markers

33 to improve the chronology and to reduce the uncertainty. These aspects show that 34 the Bayesian approach results in more robust and objective chronologies, and thus 35 in better reconstructions of environmental change over the past centuries.

36 Keywords: ${ }^{210} \mathrm{~Pb}$ sediment dating, Bayesian Statistics, Uncertainty, Marine, Coast, 37 Lake. 


\section{Introduction}

39 Historical records of global change provide essential information to identify the main

40 stressors affecting ecosystems. Such environmental information can feed models of

41 potential impact scenarios and guide the development of appropriate mitigation

42 strategies. However, because long-term instrumental records are still scarce, natural

43 archives such as sediment cores from aquatic ecosystems that accumulate

44 continuously, have become one of the most relevant resources of retrospective

45 information to establish trends of environmental changes on time-scales from years

46 to millennia or more. This information, which includes rates of change, ages of

47 events and timing differences between records, should be based on reliable 48 chronologies.

${ }^{210} \mathrm{~Pb}$ is the most widely used radionuclide to date sediment records within the

50 past $110-150$ years, a period that includes the Anthropocene, with huge global

51 changes associated with the need to provide food and energy resources to a rapidly

52 growing human population (Waters et al., 2016). ${ }^{210} \mathrm{~Pb}(\mathrm{t} / 2=22.23$ years) belongs to

53 the ${ }^{238} \mathrm{U}$ natural decay series, and its abundance in sediments $\left({ }^{210} \mathrm{~Pb}\right.$ tot $)$ results from

54 the mixture of (a) supported ${ }^{210} \mathrm{~Pb}\left({ }^{210} \mathrm{~Pb}_{\text {sup }}\right)$ produced in situ through the decay of $55{ }^{226} \mathrm{Ra}$ in the lithosphere, and (b) excess ${ }^{210} \mathrm{~Pb}\left({ }^{210} \mathrm{Pbex}\right)$ produced after ${ }^{222} \mathrm{Rn}$ decay 56 and transferred to sediments through dry and wet deposition, water column 57 scavenging and runoff. Because ${ }^{210} \mathrm{~Pb}$ ex is deposited the sediment's surface and 58 decays over time, its activity decreases with increasing sediment depth in cores from 59 undisturbed sediment deposits, enabling the establishment of chronologies (Appleby 60 and Oldfield, 1992). 
The Constant Flux (CF) model, also known as the Constant Rate of Supply

62 (CRS), (Robbins, 1978; Appleby, 1978) is a robust and widely used ${ }^{210} \mathrm{~Pb}$ dating model. It is based on the fundamental equation that establishes that ${ }^{210} \mathrm{~Pb}$ ex activities depend on the ${ }^{210} \mathrm{~Pb}_{\text {ex }}$ flux to the sediment surface and the sediment mass loading (Krishnaswamy et al., 1971; Sanchez-Cabeza and Ruiz-Fernández, 2012). The main hypothesis behind the CF model is that the ${ }^{210} \mathrm{Pbex}$ flux is constant, and this can be used to infer estimates of temporal variations of sediment accumulation rates (SAR, cm year ${ }^{-1}$ ) and mass accumulation rates (MAR, $\mathrm{g} \mathrm{cm}^{-2}$ year-1). Age calculations are based on the total inventory of ${ }^{210} \mathrm{~Pb}$ ex (i.e. the accumulated deposit per unit area), which requires estimates of ${ }^{210} \mathrm{~Pb}_{\mathrm{ex}}$ data for each core section until 71 reaching the equilibrium depth (where ${ }^{210} \mathrm{~Pb}$ tot and ${ }^{210} \mathrm{~Pb}$ sup activities become 72 indistinguishable). Therefore, missing ${ }^{210} \mathrm{~Pb}$ ex data should be estimated by 73 interpolation or, in the case of cores not reaching equilibrium, missing inventory 74 extrapolated (Appleby, 2002). These restrictive requirements might cause problems 75 in sub-optimal cores (e.g., those with incomplete ${ }^{210} \mathrm{~Pb}$ ex inventory, poorly defined $76{ }^{210} \mathrm{~Pb}$ equilibrium depth, or varying ${ }^{210} \mathrm{~Pb}$ sup). Therefore, some CF-derived age77 models may not provide reliable chronologies, especially given the extensive global 78 land use changes that have taken place over the past century.

Recently, Aquino-López et al. (2018) developed a new model for ${ }^{210} \mathrm{~Pb}$ dating 80 called Plum, which is also based on the fundamental equation and the CF 81 hypothesis. Plum is a Bayesian forward model that simultaneously integrates two 82 different processes: (1) the behaviour of the ${ }^{210} \mathrm{~Pb}$ flux and the variation of ${ }^{210} \mathrm{~Pb}$ sup 83 with depth, and (2) an age-depth function (based on Bacon, a Bayesian piece-wise 84 linear model constrained by prior information on accumulation rate and variability; 
85 Blaauw and Christen 2011). These processes are parameterized, which allows the use of a Bayesian approach. With the help of millions of Monte Carlo Markov Chain 87 (MCMC) iterations, a posterior sample can be obtained. This posterior sample combines a priori information of sediment accumulation rates, ${ }^{210} \mathrm{~Pb}$ ex flux (typically observed in a given sampling site type) and data $\left({ }^{210} \mathrm{~Pb}\right.$ tot and ${ }^{226} \mathrm{Ra}$ laboratory measurements, and potentially additional information from other radioactive isotopes such as ${ }^{137} \mathrm{Cs}$ and ${ }^{14} \mathrm{C}$ ). Within any of the iterations, Plum chooses values for both the age-depth function, which assigns ages to any depth, and the ${ }^{210} \mathrm{~Pb}$ flux and ${ }^{210} \mathrm{~Pb}_{\text {sup }}$. With these parameters and the given ${ }^{210} \mathrm{~Pb}$ 's known $\mathrm{t} / 2$, values for ${ }^{210} \mathrm{~Pb}_{\text {tot }}$ can be calculated and compared to the measurements at any depth. Plum only requires experimental data on sediment density, ${ }^{210} \mathrm{~Pb}$ tot and ${ }^{226} \mathrm{Ra}$ activities (or at least a good approximation of ${ }^{210} \mathrm{~Pb}$ sup) and the outputs include estimates of ${ }^{210} \mathrm{~Pb}$ xs flux, supported ${ }^{210} \mathrm{~Pb}$ and sediment ages. Any of these parameters are expressed as posterior distributions and $95 \%$ confidence intervals.

In comparison to the traditional implementation of the CF model, which is a reverse and deterministic model (e.g. ages are directly inferred from ${ }^{210} \mathrm{~Pb}$ tot and $101{ }^{226} \mathrm{Ra}$ laboratory data), Plum is a much more flexible forward model that allows coping with non-ideal ${ }^{210} \mathrm{~Pb}$ depth profiles (variable compaction poorly-defined equilibrium depth). In addition, it can easily handle gaps in ${ }^{210} \mathrm{~Pb}$ data or multiple measurements even from the same depth, and can include other types of dating information (e.g. ${ }^{14} \mathrm{C}$ dates, ${ }^{137} \mathrm{Cs}$ peak and tephras). In this work, we present results of a test on the efficacy and reliability of the 107 CF and Plum models using data of previously published ${ }^{210} \mathrm{~Pb}$-dated sediment cores 108 from contrasting environments (deep and shallow marine areas, a crater lake, and a 
saltmarsh) where dating difficulties were encountered. Our hypothesis was that Plum

110 is better than CF in managing the assumptions involved with the ${ }^{210} \mathrm{~Pb}$ CF model

111 and in estimating age uncertainties. The age models obtained were contrasted with

112 stratigraphic markers (e.g. ${ }^{137} \mathrm{Cs}$, Pu isotopes) for validation.

\section{2. Study area}

114 The sediment cores were collected from four contrasting environments in Mexico, in 115 order to reconstruct the temporal trends of a range of global change indicators 116 (Figure 1). Core IXW-500 (Ruiz-Fernández et al., 2019a) was collected from a deep117 sea area in the southern Gulf of Mexico (Atlantic Coast) characterized by strong 118 fluvial input, natural oil seeps, intense maritime traffic and offshore oil extraction 119 activities, and was used to assess trace metal contamination.

120 Core Tehua-Il (Ruiz-Fernández et al., 2009b) was sampled from a shallow 121 marine area in the Tehuantepec Gulf (Pacific Coast) characterized by high 122 productivity associated with fluvial inputs and intense upwelling, which sustains 123 relevant commercial fisheries (e.g. tuna, shrimp and shark) and experiences strong 124 shipping traffic owing to oil production and distribution activities. For this core, 125 temporal variations of sediment accumulation rates were determined in order to 126 reconstruct land use changes.

127 Core All (Ruiz-Fernández et al., 2016) was sampled to estimate rates of sea 128 level rise at a saltmarsh in Estero de Urías (Gulf of California, Pacific Coast) an 129 anthropized lagoon that hosts a harbour with shipping activities ranging from 130 cabotage and fishing (mainly tuna and shrimp) to passenger cruises, and which also 131 receives untreated domestic and industrial wastes. 
Finally, core SAMO2014-2 (Ruiz-Fernández et al., 2019b) was collected to 133 determine mass accumulation rates in Lake Santa Maria del Oro, a 2-km diameter 134 and 65m deep oligomictic and mesotrophic crater lake (Cardoso-Mohedano et al., 135 2019). The lake is mainly used for recreational activities, and it is located within the 136 Trans-Mexican Volcanic Belt at $65 \mathrm{~km}$ from the Pacific Coast.

\section{Methods}

138 The sediment cores were collected with transparent PVC tubes of different internal 139 diameter and assisted by different types of samplers (see Table 1 for sampling 140 details). The cores were extruded and cut into contiguous $1 \mathrm{~cm}$ thick sections. 141 Samples were weighed before and after freeze-drying; sediment bulk density $\left(\mathrm{g} \mathrm{cm}^{-}\right.$ $142{ }^{3}$ ) was calculated as the ratio of the total dry mass and the volume (from diameter 143 and thickness) of each core section.

144 3.1. Laboratory analysis

145 All sediment cores were analysed in the Sediment Dating Academic Service at 146 UNAM, following the methodology described in previous publications (Ruiz147 Fernández et al., 2009, 2016, 2019a, 2019b). To summarise, ${ }^{210} \mathrm{~Pb}$ tot activities were 148 measured using alpha spectrometry (Alpha Ensemble Ortec/Ametek) according to 149 Ruiz-Fernández and Hillaire-Marcel (2009). ${ }^{210} \mathrm{~Pb}_{\text {sup }}$ activities were estimated using 150 gamma spectrometry measurements of ${ }^{226} \mathrm{Ra}$ activities (through its daughter 151 radionuclide ${ }^{214} \mathrm{~Pb}, 352 \mathrm{keV}$ ) using a low-background Ortec HPGe well-detector 152 (Ruiz-Fernández et al., 2014). ${ }^{210} \mathrm{Pbxs}$ activities were determined using the difference 153 between ${ }^{210} \mathrm{~Pb}$ tot and ${ }^{210} \mathrm{~Pb}$ sup activities. To validate the ${ }^{210} \mathrm{~Pb}$-derived chronologies, 154 the activity profiles of ${ }^{137} \mathrm{Cs}$ against depth were determined by gamma-ray 155 spectrometry (662 keV) in all cores, and plutonium isotopes were determined by i) 
alpha-particle spectrometry for core SAMO14-2 (Ruiz-Fernández et al., 2019b), ii)

157 low-energy accelerator mass spectrometry for core EUIII (in Centro Nacional de 158 Aceleradores, Spain; Ruiz-Fernández et al., 2016) and iii) mass spectrometry in 159 Spiez Laboratory (Switzerland) for core IXW-500.

\section{2. ${ }^{210} \mathrm{~Pb}$-derived chronologies}

161 In the original papers, chronologies, mass and sediment accumulation rates were estimated with the constant flux (CF) model (Appleby and Oldfield, 1978; Robbins, 1978; Sanchez-Cabeza and Ruiz-Fernández, 2012). Dating uncertainties in core Tehua-II were calculated using quadratic propagation uncertainty, whereas in the other cores they were estimated by Monte Carlo simulation with $10^{5}$ simulations (Sanchez-Cabeza et al., 2014).

The Plum age-depth models were obtained using the default settings. These settings dictate the prior distributions used for the supported ${ }^{210} \mathrm{~Pb},{ }^{210} \mathrm{~Pb}$ flux, and sedimentation rate and its variability (used within each Bacon section), as well as the thickness of Bacon sections. By default, Plum uses 1-cm thick Bacon sections

171 (whereas Bacon's default is 5, which is probably too restrictive to model sedimentation close to the surface). The default prior distribution for the supported ${ }^{210} \mathrm{~Pb}$ parameters is a gamma distribution with a mean of $15 \mathrm{~Bq} \mathrm{~kg}^{-1}$ and a shape

174 parameter of 2 . For core IXW500, Plum used the ${ }^{226}$ Ra measurements to obtain estimates for supported ${ }^{210} \mathrm{~Pb}$ at multiple depths, whereas for the other cores supported ${ }^{210} \mathrm{~Pb}$ was assumed to be constant throughout each core. For the ${ }^{210} \mathrm{~Pb}$

177 flux, Plum uses a gamma distribution with a mean of $50 \mathrm{~Bq} \mathrm{~m}^{-2} \mathrm{yr}^{-1}$ and a shape 178 parameter of 2. Plum also uses an upper age limit, for which it uses a parameter set 179 to $A_{l}=0.1$ by default, which is defined as the remaining unmeasured ${ }^{210} \mathrm{~Pb}_{\text {ex. }}$. This 
180

181 according to the inferred ${ }^{210} \mathrm{Pbex}$ flux. Plum also can use information from time-

markers such as the human-made peak in ${ }^{137} \mathrm{Cs}$ to refine the age-depth model, but 183 this was ignored as we wanted to observe only the behaviour of the ${ }^{210} \mathrm{~Pb}$ data on 184 their own.

\section{Results}

Figures 2, 3, 4 and 5 show the comparisons between the ${ }^{210} \mathrm{~Pb}$-derived chronologies using the CF and Plum dating models.

\subsection{TEHUA-II}

189 In the case of TEHUA-II (Figure 2), both models agreed well with each other 190 throughout the chronologies. The CF confidence intervals overlapped Plum's 191 credible intervals, i.e. Plum provided narrower intervals. In this case, Plum was able 192 to extend the chronology by up to two decades, because fewer measurements were 193 discarded in order to infer the supported ${ }^{210} \mathrm{~Pb}$. Both models agreed quite well with 194 the 1963 time-marker.

195 4.2. $E U-I I I$

196 Figure 3 shows the comparison between the CF and Plum age-models of core EU197 III. In this case, the chronologies agreed well with each other, providing similar age 198 estimates and similar credible and confidence intervals. Again, Plum was able to 199 extend the chronology for several decades as several more data points are used to 200 infer the chronology: CF inferred a chronology up to a depth of $27.5 \mathrm{~cm}$, whereas 201 Plum reached a depth of $39 \mathrm{~cm}$. Regarding the 1963 time marker, Plum seems to 202 agree better as the CF model provided younger ages and its uncertainty was 203 insufficient to enclose the time marker. 
205 SAMO14-2's chronology (Figure 4) showed that the age estimates are in good 206 agreement and both models enclose the time marker within its intervals. On the other 207 hand, the model's uncertainty estimates show largeed differences, with Plum 208 providing more conservative uncertainty estimates. Regarding the length of the 209 chronology, Plum was again able to extend the chronology by several decades by 210 its use of fewer measurements to infer the supported ${ }^{210} \mathrm{~Pb}$ value.

\section{4.4. IXW-500}

212 In this case, the CF- and Plum- derived age models resulted in significant differences 213 (Fig. 5) at different core depths. In comparison with CF ages, Plum ages were older 214 in the segments surface $-4 \mathrm{~cm}$ and $8-12 \mathrm{~cm}$, but comparable within the segments $2155-8 \mathrm{~cm}$ and below $12 \mathrm{~cm}$. Plum provided a more conservative age estimate, with 216 larger and more credible intervals than the CF model. In this particular case, The 217 Plum-derived age model comprised almost twice the CF age period (age estimate 218 of 160 years at $15 \mathrm{~cm}$ depth and 308 years at $29 \mathrm{~cm}$ depth). This was caused by CF 219 having to discard the 5 bottom measurements, whereas Plum was able to extract 220 information from them.

The considerable differences between the models could be caused by the peculiar ${ }^{226}$ Ra profile of this core (shown as blue dots in the supported ${ }^{210} \mathrm{~Pb}$ panel in Figure 4). The largest difference between the age models was observed at mid-

224 depth, where a minimum ${ }^{210} \mathrm{Pbex}$ in activity occurs, caused by large ${ }^{226} \mathrm{Ra}$ activity. 225 This also resulted in both models presenting a change in behaviour at this depth, 226 with a larger accumulation rate at depths lower than $9 \mathrm{~cm}$. In this case, refining the 227 chronology using more information (e.g. ${ }^{137} \mathrm{Cs}$ ) could be of help, as Plum can include 
228 these time markers to the likelihood function in order to obtain an integrated 229 chronology.

230 It is important to note that both total ${ }^{210} \mathrm{~Pb}$ and ${ }^{226} \mathrm{Ra}$ at the five deepest samples 231 were very similar, i.e. equilibrium was reached. In this case, Plum uses the 232 information provided by the rest of the core and the prior distribution to provide an 233 informed extrapolation.

\section{5. Discussion}

\subsection{Tehua-II and EU-III}

As all sections of these cores were measured down to equilibrium, as expected both 237 models provided similar results. In the case of TEHUA-II, Plum provided narrower 238 credible intervals, which are a result of the use of the Bacon age-depth function, 239 instead of the decay equation used by the CF model. On the other hand, the age240 models for EU-III agreed well and reconstructed similar uncertainty intervals. Plum 241 was able to extend the chronology by a couple of decades in the case of TEHUAll 242 and by more than $100 \mathrm{yr}$ in the case of EU-III. This is a result of Plum's integration 243 of supported ${ }^{210} \mathrm{~Pb}$ in the inference process, removing the need to discard the 244 lowermost few measurements.

245 5.2. SAMO14-2

246 SAMO14-2 presents an interesting case as relatively few data points were available

247 for the inference. Both models presented overlapping results. In this case, Plum 248 provided wider intervals as a result of the low number of samples measured for this 249 core. The CF model provided very precise age estimates, apparently a positive 250 outcome, but considering that less than $25 \%$ of the core sections were measured 251 (10 measurements of $1 \mathrm{~cm}$ sections were used to infer the chronology to a depth of 
$25241 \mathrm{~cm}$ ), the more conservative intervals provided by Plum are more coherent. This

253 is an important consequence of the interpolations used to estimate the ${ }^{210} \mathrm{~Pb}_{\mathrm{ex}}$ 254 inventories, which do not consider the error caused by the absence of 255 measurements. Interestingly, something similar appears to happen in simulated and 256 real-world ${ }^{14} \mathrm{C}$-dated cores modelled using classical and Bayesian age-models 257 (Blaauw et al. 2018): whereas Bayesian age-models become more precise with 258 increasing dating densities (they 'learn'), classical age-models such as linear 259 interpolation do not.

260 5.3. IXW-500

261 This core presented significant differences between each model. Plum inferred lower 262 levels of supported ${ }^{210} \mathrm{~Pb}$ at $8-10 \mathrm{~cm}$ depths in comparison to the measured ${ }^{226} \mathrm{Ra}$ 263 (see Figure 5). It is at these depths where both models show their largest 264 discrepancies. In this case, more measurements around the spike of ${ }^{226} \mathrm{Ra}$ could 265 help Plum to model these unusual spikes. Also, Plum can use other time markers 266 such as ${ }^{137} \mathrm{Cs}$ to refine the chronology.

267 5.4. Plum extended chronologies

268 As shown, Plum is able to obtain longer chronologies. In some cases, the extension 269 is a result of fewer samples being used exclusively to infer supported ${ }^{210} \mathrm{~Pb}$ and/or 270 the use of the final sample with ${ }^{210} \mathrm{~Pb}$ ex not being discarded (which is common 271 practice when using the CF model). These extensions provide an accurate 272 chronology with an uncertainty similar to the rest of the chronology. In other cases, 273 like IXW-500, it is the result of using ${ }^{226}$ Ra concentrations combined with a sediment 274 with ${ }^{210} \mathrm{~Pb}$ in equilibrium. Plum provides a much larger extension in these 275 chronologies, but this should be taken with extra caution, since at depths below 
276 where ${ }^{210} \mathrm{Pbex}$ is available, age uncertainties become considerably higher and 277 precision decreases. These extensions are a linear simplification, which uses 278 information from both the data and the prior distributions for the accumulation rate 279 and variability. Under simulation, we have observed that these extensions become 280 more inaccurate with depth, but the credible intervals (larger than in the rest of the 281 chronology) are able to capture the true age. These extensions are rather qualitative 282 and should not be used to obtain conclusions on sedimentary processes and 283 records. Because simulations are not within the scope of the present study, these 284 are left for future research.

285 5.5. CF rapid accumulation

286 The CF model was constructed using the decay equation as its basis, which resulted

287 in a logarithmic age-depth function; $t(x)=\lambda^{-1} \log \left(\frac{A(0)}{A(x)}\right)$. This age-depth function 288 works well in the most recent part of the sediment, but as the remaining activity $A(x)$ 289 gets close to 0 , the age function rapidly tends to infinity, resulting in an artificial 290 increase of accumulation rates. This increase is not caused by natural sources but 291 it is a result of the mathematical structure of the model and should not be included 292 in interpretations. On the other hand, because Plum uses an independent age-depth 293 function, it does not show this artificial increase in accumulation, providing a more 294 realistic age-depth function at deeper parts of the sediment.

295 5.6. Overall considerations

296 When CF model users are confronted with a new core, a number of decisions must 297 be made based on the available information. Because of resource constraints, 298 typically not all core sections are measured and interpolation techniques are needed, 
which may induce an experimental error. By design, Plum does not need any kind 300 of interpolation and solely relies on the existing data. While both the CF model and 301 Plum should produce better age-models with more data (i.e. more information), Plum results are undoubtedly more reliable when some data are missing.

The reliability of measurement can also be sometimes an issue. For example,

304 the CF radiochronologist might decide that a measurement is an outlier, or that concentrations close or below $0 \mathrm{~Bq} \mathrm{~kg}^{-1}$ are zero. In the case of Plum, this is not an issue, as the system will choose, based on Bayesian statistics, which is the best set of activities and, in some cases, disregard an outlier or ignore low (or negative) concentrations, without human intervention.

One of the critical decisions that must be taken when using the CF model is 310 the selection of the equilibrium depth of the core, i.e., the depth where the ${ }^{210} \mathrm{Pbex}$ 311 reaches zero and from where the total ${ }^{210} \mathrm{~Pb}$ ex inventory can be calculated. The 312 equilibrium depth mainly depends on the unambiguous knowledge of the ${ }^{210} \mathrm{~Pb}_{\text {sup }}$ 313 value. This is often difficult to ascertain owing to i) large relative uncertainties of $314{ }^{210} \mathrm{Pbex}$, when calculated by subtraction of ${ }^{210} \mathrm{~Pb}$ and ${ }^{226} \mathrm{Ra}$ (or an estimated ${ }^{210} \mathrm{~Pb}$ sup), 315 which can be very similar at the core bottom, and ii) changes in sediment 316 composition which can produce variations of ${ }^{210} \mathrm{~Pb}_{\text {sup }}$ activities along a core (e.g. 317 Carnero-Bravo et al. 2016), which will affect the total ${ }^{210} \mathrm{~Pb}$ xs inventory and thus the 318 core age, as higher inventories will cause younger ages and vice versa. Therefore, 319 depending on the core's ${ }^{210} \mathrm{~Pb}$ activity profile, small variations of specific activities 320 could produce age variations amounting to decades. A relevant feature of Plum is 321 that ${ }^{210} \mathrm{~Pb}$ sup is not a a value to be provided by the user but a parameter to be inferred. 322 Plum uses data to infer ${ }^{210} \mathrm{~Pb}$ sup, which can be ${ }^{226} \mathrm{Ra}$ measurements or ${ }^{210} \mathrm{~Pb}$ which 
323 reached equilibrium. If only ${ }^{210} \mathrm{~Pb}$ is available, Plum runs a pre-analysis based on a

324 linear regression, where the segment which provides the largest $p$-value (and thus 325 lower variability) is suggested to be used exclusively to infer ${ }^{210} \mathrm{~Pb}$ sup. Because the 326 -value is affected by sample size, this pre-analysis should be confirmed by the user, 327 but it has provided reasonable results in several simulations and real cores. This 328 reduces considerably the calculation efforts and decisions of the user, and 329 maximizes the confidence in the ${ }^{210} \mathrm{~Pb}$ sup value.

Sometimes the ${ }^{210} \mathrm{~Pb}$ profile is incomplete, i.e. ${ }^{210} \mathrm{~Pb}$ does not reach 331 equilibrium. In this case, CF users need to estimate the missing inventory from either 332 a bottom constant accumulation rate, or by using a reference date (e.g. the ${ }^{137} \mathrm{Cs}$ 333 maximum). In the case of Plum this is not needed, as even in these cases Plum will 334 estimate the total ${ }^{210} \mathrm{Pbex}$ flux by Bayesian statistics.

335 In overall, these and other decisions may cause different scientists, or even 336 the same scientist at different moments, to produce different chronologies with the 337 same data set and using the same model. As Plum uses existing information, age 338 models should be identical (as long as the prior parameters are the same) and the 339 user-based bias should largely reduced. In this sense, Plum is clearly more objective 340 and we suggest that it should be widely used by ${ }^{210} \mathrm{~Pb}$ radiochronologists.

341 In this comparison study, only ${ }^{210} \mathrm{~Pb}$ measurements were used to produce 342 chronologies. However, for core IXW-500 additional nuclides were measured, 343 including ${ }^{137} \mathrm{Cs}$, which has known historical peaks caused by radioactive releases 344 into the atmosphere. Such peaks are regularly used to validate or adjust ${ }^{210} \mathrm{~Pb}$-based 345 chronologies. Plum can integrate such information, as well as ${ }^{14} \mathrm{C}$ and other dates, 346 into the ${ }^{210} \mathrm{~Pb}$ chronology. 


\section{Conclusions}

348 The application of the CF ${ }^{210} \mathrm{~Pb}$ sediment dating model requires from the

349 radiochronologist several inputs, such as the equilibrium depth and data 350 interpolation when not all sections are measured, a rather common case. However, 351 with the Bayesian approach used by Plum this is no longer needed, thus making the 352 dating process less subjective and more reproducible.

353 The comparison of both approaches show that Plum provides similar results 354 to the classical CF model, with the added benefits of providing more precise 355 uncertainty estimates when sampling density is high (like in the case of TEHUA-II 356 and EU-III), and providing more realistic uncertainty estimates where few samples 357 are available (SAMO14-2). Also, Plum is not affected by artificial increases of 358 sedimentation in the deepest part of the sediment, unlike the CF model where the 359 logarithmic age-function tends to infinity as background is reached. This allows the 360 user to interpret dates deeper in the core without being affected by artificial increases 361 in the sedimentation.

$362 \quad$ Plum' older ages, obtained by the usability of more data, appears to be in 363 disagreement with previous chronology limits (Appleby, 1998). This point was 364 previously addressed by Aquino-López el at. (2018), as by using simulations it was 365 shown that these older ages remained accurate when the core is fully sampled. 366 These older ages are also accompanied by a more realistic uncertainty (much larger 367 credible intervals), and should be handled with caution, even more when the core is 368 not fully sampled. Users and/or studies which require less uncertainty should 369 consider discarding these older ages or providing the model with other time markers, 
which will improve the levels of uncertainty and help the model provide a more

371 precise chronology.

The ability of adding extra information such as ${ }^{137} \mathrm{Cs}$, radiocarbon dates

373 and/or tephra dates can be used for both validating the chronology or improving it.

374 Because Plum uses raw ${ }^{210} \mathrm{~Pb}$ to create the chronology, multiple isotope

375 chronologies are possible without having to pre-model the ${ }^{210} \mathrm{~Pb}$ dates. This quality

376 should not be underestimated, as the effects of the bias in the deepest part of the

377 sediment presented by the CF model have not yet been studied. Because of all these

378 considerations, we believe that Plum has the potential of providing more robust and

379 objective ${ }^{210} \mathrm{~Pb}$ chronologies.

380 Acknowledgements

381 The authors acknowledge partial financial support from a Royal Society-Newton 382 Mobility Grant (Dating the decadal-scale dynamics of ENSO and pollution trends 383 from crater lake sediments in Nayarit, western tropical Mexico), CONACYT (PDCPN 384 2015-01/473, CONACYT-CNR C0013-2016-05-277942, SEMARNAT-2016-01385 278634), UNAM (PAPIIT IN110518 and IN104718; LANCAD-UNAM-DGTIC-273). 386 Part of this work was funded by a CONACYT postgraduate scholarship 411036 to 387 Marco A. Aquino-López at Queen's University Belfast. Authors are grateful to the 388 technical support received by L.H. Pérez-Bernal, León Felipe Álvarez, H. Bojórquez389 Leyva, S. Rendón-Rodríguez, G. Ramírez Reséndiz and C. Suárez-Gutiérrez.

\section{Data Availability}

391 Sediment data are available as supplementary material.

\section{Supplementary material}

393 - Data used for ${ }^{210} \mathrm{~Pb}$ dating with Plum. 


\section{References}

395 Appleby, P. G., Oldfield, F. (1978). The calculation of lead-210 dates assuming a 396 constant rate of supply of unsupported ${ }^{210} \mathrm{~Pb}$ to the sediment. Catena, 5(1), 18.

Appleby, P. G., Oldfield, F. (1992). Application of lead-210 to sedimentation studies. Uranium-Series Disequilibrium: Applications to Earth, Marine, and Environmental Sciences, 2nd edition. Oxford: Clarendon, 731-778.

401

402

403

404

405

406

407

408

409

410

Appleby, P. G. (1998). Dating recent sediments by 210Pb: Problems and solutions. Proc. 2nd NKS/EKO-1 Seminar, Helsinki, 2-4 April 1997, STUK, Helsinki, pages $7-24$.

Appleby, P. G. (2002). Chronostratigraphic techniques in recent sediments. In Tracking environmental change using lake sediments (pp. 171-203). Springer, Dordrecht.

Aquino-López, M. A., Blaauw, M., Christen, J. A., Sanderson, N. K. (2018). Bayesian analysis of ${ }^{210} \mathrm{~Pb}$ dating. Journal of Agricultural, Biological and Environmental Statistics, 23(3), 317-333.

Blaauw, M. Christen, J. A. (2011). Flexible paleoclimate age-depth models using an autoregressive gamma process. Bayesian Analysis, 6(3), 457-474.

Blaauw, M., Christen, J.A., Bennett, K.D., Reimer, P.J., 2018. Double the dates and go for Bayes - impacts of model choice, dating density and quality on chronologies. Quaternary Science Reviews, 188, 58-66

Cardoso-Mohedano, J. G., Sanchez-Cabeza, J. A., Ruiz-Fernández, A. C., PérezBernal, L. H., Lima-Rego, J., Giralt, S. (2019). Fast deep water warming of a subtropical crater lake. Science of the Total Environment, 691, 1353-1361. 
418 Carnero-Bravo, V., Sanchez-Cabeza, J. A., Ruiz-Fernández, A. C., Merino-lbarra, 419 M., Hillaire-Marcel, C., Corcho-Alvarado, J. A., Röllin, S., Diaz-Asencio, M., 420 Cardoso-Mohedano, J.G., \& Zavala-Hidalgo, J. (2016). Sedimentary records of recent sea level rise and acceleration in the Yucatan Peninsula. Science of the Total Environment, 573, 1063-1069.

423

424

425

426

427

428

429

430

431

432

433

434

435

436

437

438

439

440

441

Krishnaswamy, S., Lal, D., Martin, J., Meybeck, M. (1971). Geochronology of Lake Sediments. Earth and Planetary Science Letters 11: 407-14.

Robbins J. A. (1978) Geochemical and geophysical applications of radioactive lead isotopes. In Biochemistry of Lead (ed. J. O. Nriagu). Elsevier, Amsterdam, pp. 85-393.

Ruiz-Fernández A.C., Hillaire-Marcel C. (2009a). ${ }^{210} \mathrm{~Pb}-$ derived ages for the reconstruction of terrestrial contaminant history into the Mexican Pacific coast: Potential and limitations. Marine Pollution Bulletin 59, 134-145.

Ruiz-Fernández A. C., Hillaire-Marcel C., de Vernal A., Machain-Castillo M. L., Vásquez L., Ghaleb B., Aspiazu-Fabián, J.A., Páez-Osuna F. (2009b). Changes of coastal sedimentation in the Gulf of Tehuantepec, South Pacific Mexico, over the last 100 years from short-lived radionuclide measurements. Estuarine Coastal and Shelf Science 82, 525-536.

Ruiz-Fernández, A. C., Maanan, M., Sanchez-Cabeza, J. A., Pérez-Bernal, L. H., López-Mendoza, P., Limoges, A. (2014). Chronology of recent sedimentation and geochemical characteristics of sediments in Alvarado Lagoon, Veracruz (southwestern gulf of Mexico). Ciencias Marinas, 40(4), 291-303.

Ruiz-Fernández A. C., Sanchez-Cabeza J. A., Serrato de la Peña J. L., Perez-Bernal L. H., Cearreta, A., Flores-Verdugo F., M. L. Machain-Castillo, Chamizo E., 
García-Tenorio R., Queralt I., Dunbar R. B., Mucciarone D.A., Diaz-Asencio M. (2016). Accretion rates in coastal wetlands of the southeastern Gulf of California and their relationship with sea level rise. The Holocene 26, 7, 11261137.

Ruiz-Fernández A.C., Sanchez-Cabeza J.A., Pérez-Bernal L. H., Gracia-Gasca A. (2019a). Spatial and temporal distribution of heavy metal concentrations and enrichment in the Southern Gulf of Mexico. The Science of the Total Environment 651, Part 2, 3174-3186.

Ruiz-Fernández A.C., Sanchez-Cabeza J. A., Hernández-Rivera D.M., Pérez-Bernal

Sanchez-Cabeza J.A., Ruiz-Fernández

A.C. (2012). ${ }^{210} \mathrm{~Pb}$ sediment radiochronology: an integrated formulation and classification of dating models. Geochimica et Cosmochimica Acta 82, 183-200.

Sanchez-Cabeza J. A., Ruiz-Fernández AC, Ontiveros Cuadras JF, Pérez Bernal LH, Olid C (2014). Monte Carlo uncertainty calculation of ${ }^{210} \mathrm{~Pb}$ chronologies and accumulation rates of sediments and peat bogs. Quaternary

461 Waters, C. N., Zalasiewicz, J., Summerhayes, C., Barnosky, A. D., Poirier, C., 462 Gałuszka, A., Cearreta, A., Edgeworth, M., Ellis, E.C., Ellis, M., Jeandel, C., Leinfelder, R., McNeill, J. R., Richter, D. B., Steffen, W., Syvitski, J., Vidas, D., Wagreich, M., Williams, M., Zhisheng, A., Grinevald, J., Odada, E., Oreskes, 

distinct from the Holocene. Science, 351(6269), aad2622.

467 


\section{Figure captions}

469 Figure 1. Geographical locations where sediment cores were collected.

470 Figure 2. Plum and CF age-depth models for TEHUA-II. Plum 95\% credible intervals

471 and mean are shown as red dashed lines, and dark shadow show some iterative

472 chronologies obtained by the MCMC. The CF age-depth model is shown in blue,

473 using linear interpolation between neighbouring data points used to construct the

474 model. Bottom boxes show depths where samples were analyzed. The orange box

475 shows the ${ }^{137}$ Cs 1963 time marker.

476 Figure 3. Plum and CF age-depth models for core EU-III. For explanation of symbols 477 and colours, see Fig. 2.

478 Figure 4. Plum and CF age-depth models for SAMO14-2. For explanation of 479 symbols and colours, see Fig. 2.

480 Figure 5. Plum and CF age-depth models for core IXW-500. For explanation of 481 symbols and colours, see Fig. 2. In the "Supported ${ }^{210} \mathrm{~Pb}$ " upper panel, black dots 482 represent Plum simulations, blue dots are the mean of the simulated values and red 483 dots are the ${ }^{226}$ Ra measurements 
485 Table 1. Sampling information for sediment cores from Mexican marine and 486 lacustrine areas.

\begin{tabular}{|c|c|c|c|c|c|}
\hline Core ID & Coordinates & $\begin{array}{l}\text { Sampling date } \\
\text { and depth (m) }\end{array}$ & $\begin{array}{l}\text { Length } \\
(\mathrm{cm})\end{array}$ & $\begin{array}{l}\text { Sediment } \\
\text { characteristics }\end{array}$ & $\begin{array}{l}\text { Corer type } \\
\text { and internal } \\
\text { diameter } \\
\text { (cm) }\end{array}$ \\
\hline $1 X W-500^{a}$ & $\begin{array}{l}19^{\circ} 26.649^{\prime} \mathrm{N} \\
93^{\circ} 53.323^{\prime} \mathrm{W}\end{array}$ & $\begin{array}{l}06 / 08 / 2015 \\
1010\end{array}$ & 25 & $\begin{array}{l}\text { Marine muddy } \\
>94 \% \text { silt + clay }\end{array}$ & $\begin{array}{l}\text { Multicorer } \\
9.5\end{array}$ \\
\hline TEHUA-II & $\begin{array}{l}15^{\circ} 59.987^{\prime} \mathrm{N} \\
94^{\circ} 48.469^{\prime} \mathrm{W}\end{array}$ & $\begin{array}{l}15 / 10 / 2004 \\
67\end{array}$ & 18 & $\begin{array}{l}\text { Marine sandy } \\
>75 \% \text { sand }\end{array}$ & $\begin{array}{l}\text { Reineck } \\
7\end{array}$ \\
\hline EU-IIIC & $\begin{array}{l}23^{\circ} 09.322^{\prime} \mathrm{N} \\
106^{\circ} 19.672^{\prime} \mathrm{W}\end{array}$ & $\begin{array}{l}05 / 05 / 2012 \\
0\end{array}$ & 50 & $\begin{array}{l}\text { Coastal hypersaline } \\
>60 \% \text { silt }\end{array}$ & $\begin{array}{l}\text { Push core } \\
10\end{array}$ \\
\hline SAMO14-2 ${ }^{d}$ & $\begin{array}{l}21^{\circ} 22.187^{\prime} \mathrm{N} \\
104^{\circ} 34.335^{\prime} \mathrm{W}\end{array}$ & $\begin{array}{l}28 / 04 / 2019 \\
48\end{array}$ & 78 & $\begin{array}{l}\text { Lacustrine } \\
>80 \% \text { silt }\end{array}$ & $\begin{array}{l}\text { Uwitec }^{\mathrm{TM}} \\
8.6\end{array}$ \\
\hline
\end{tabular}

487 aRuiz-Fernández et al., 2019a; ' Ruiz-Fernández et al., 2009b, ' Ruiz-Fernandez et 488 al., 2016; dRuiz-Fernandez et al., 2019b. 


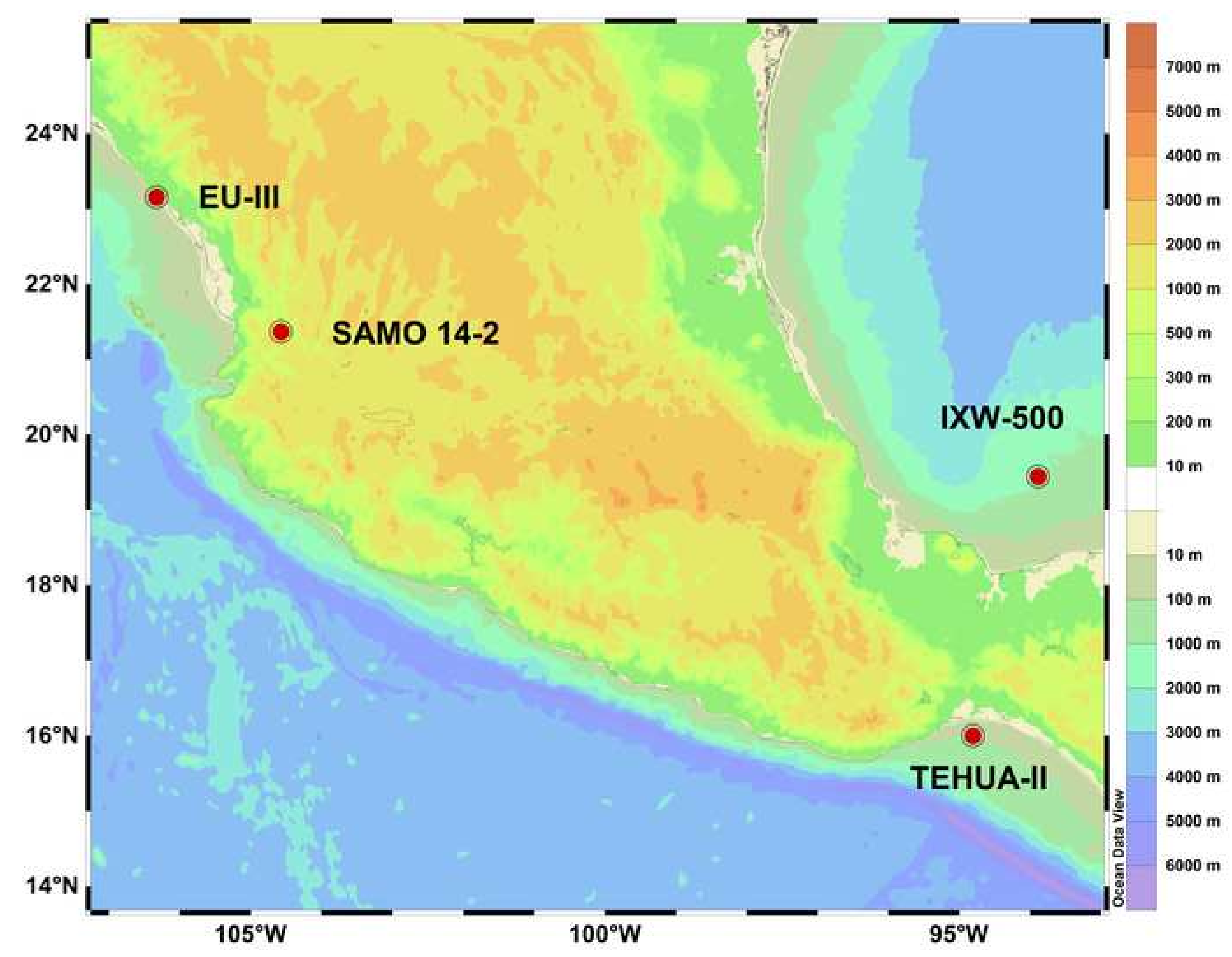



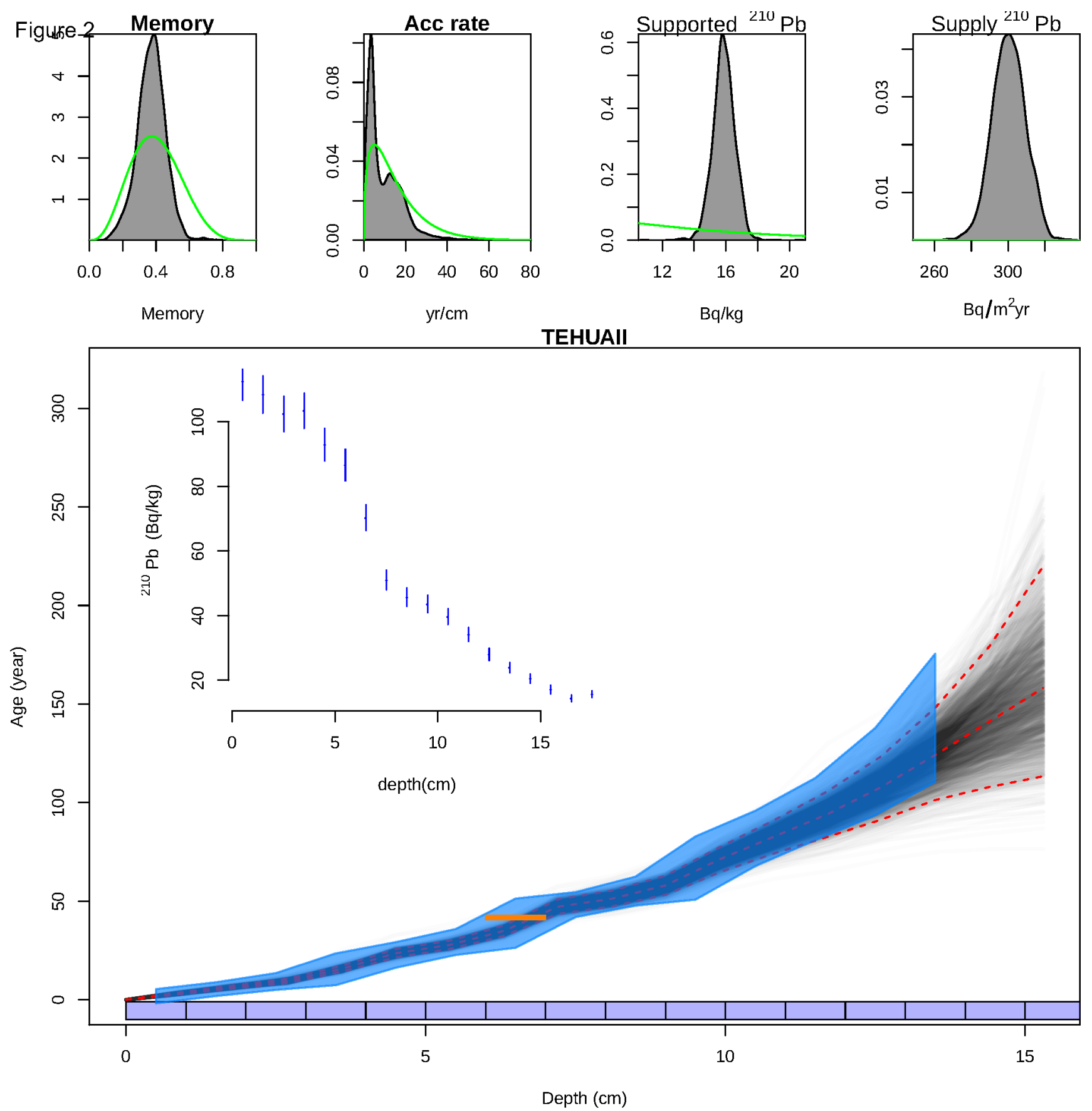

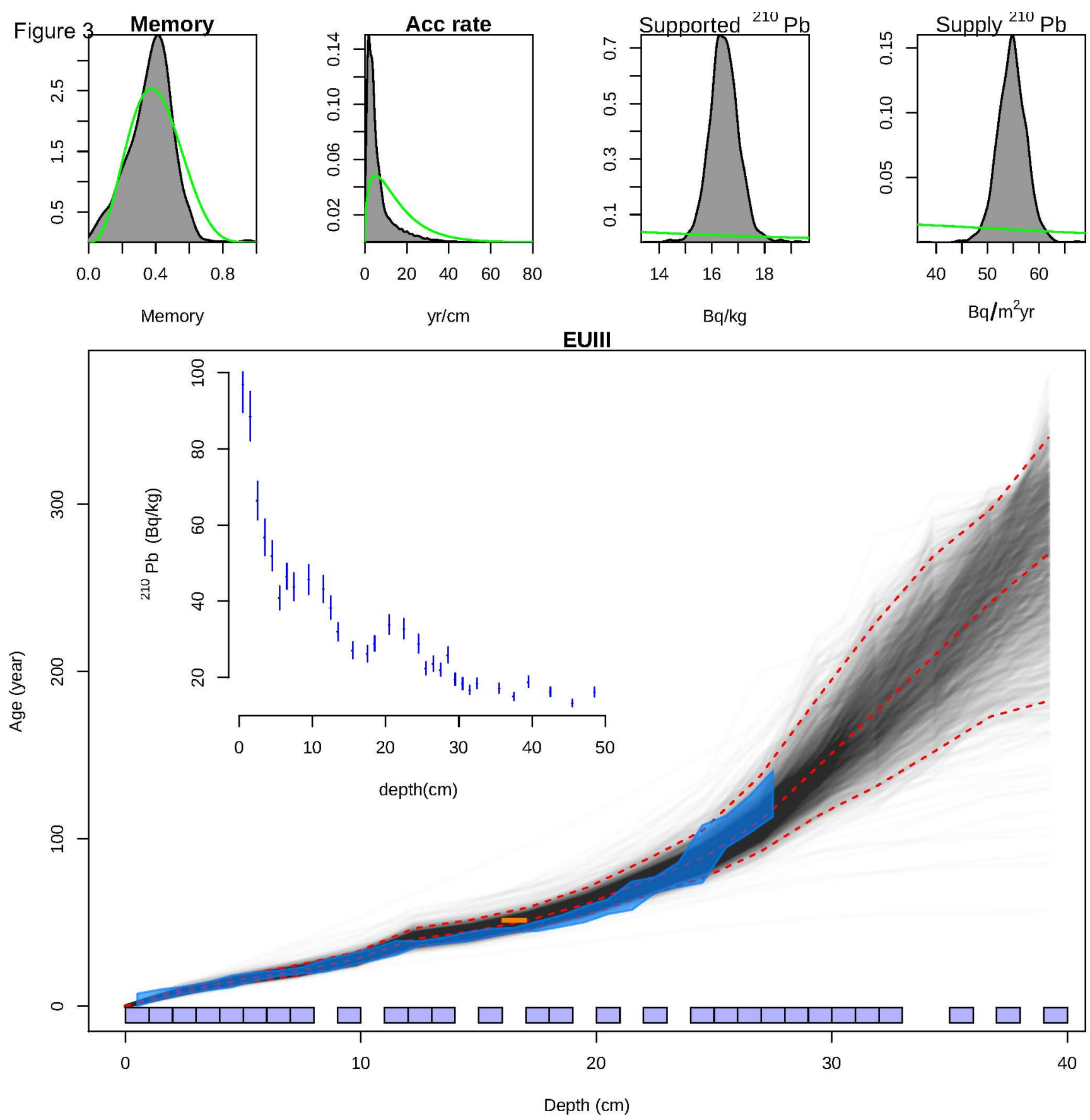

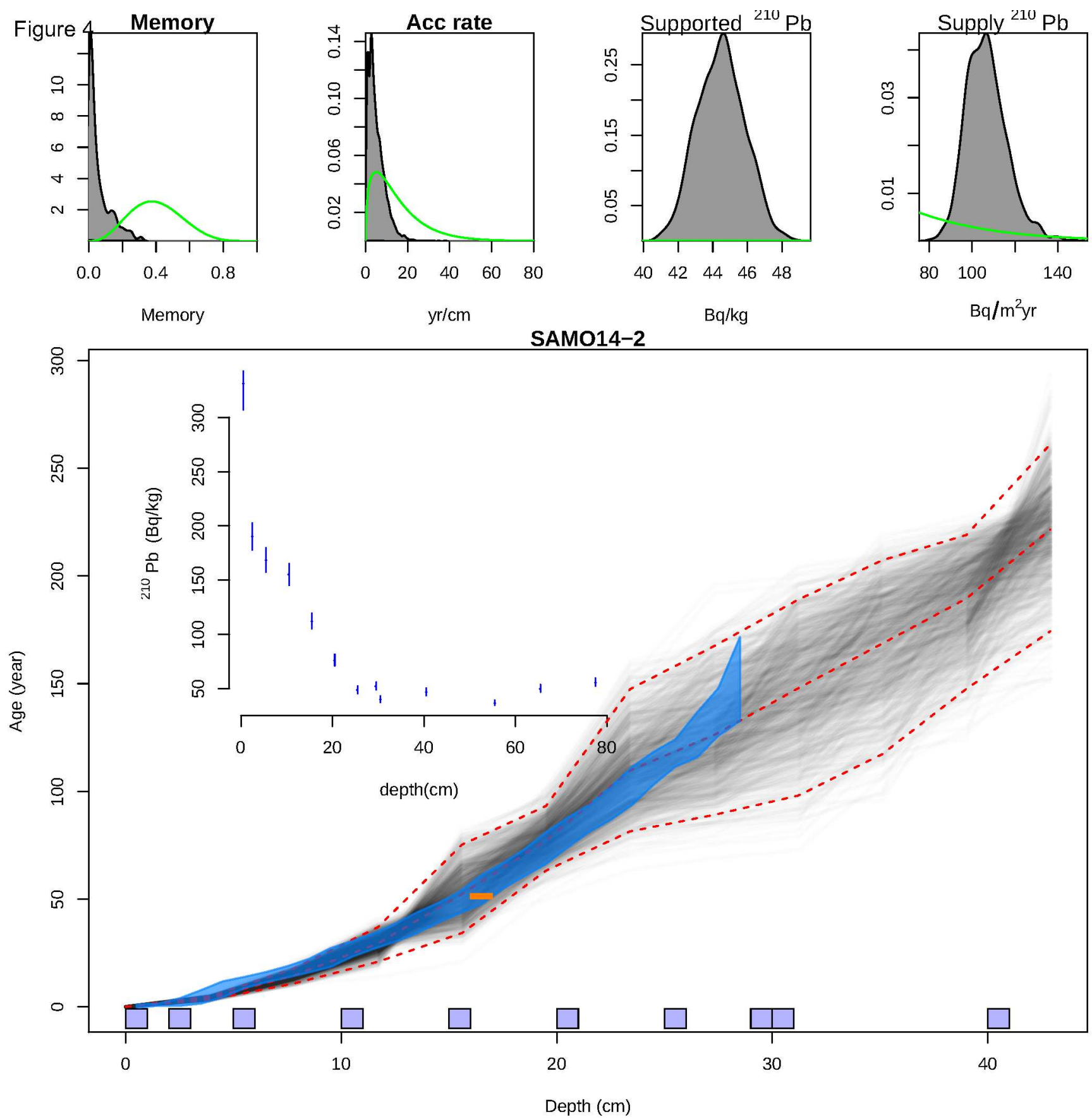

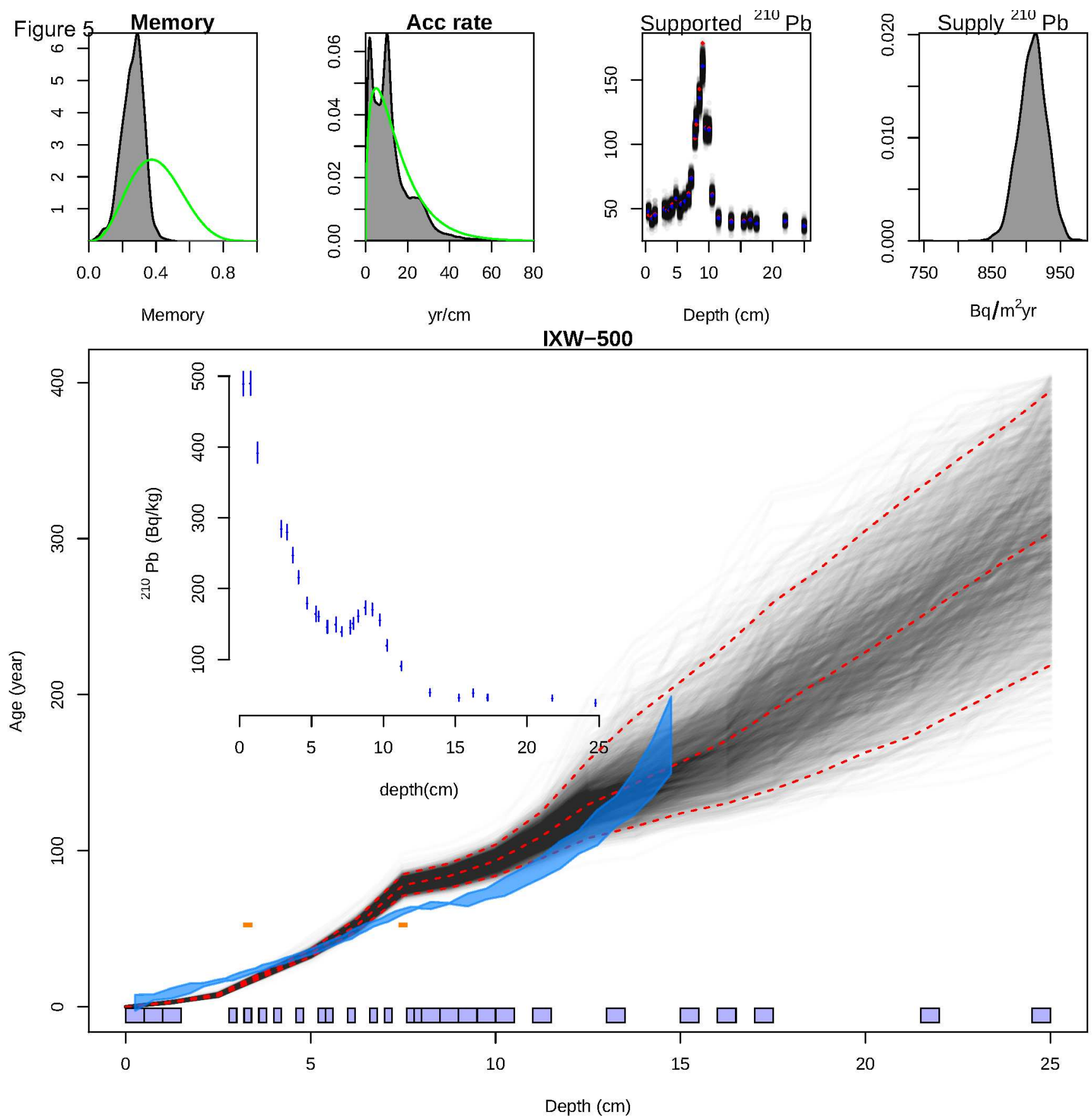
Click here to access/download RDM Data Profile XML

DataProfile_4410649.xml 


\section{Declaration of interests}

$\bigotimes$ The authors declare that they have no known competing financial interests or personal relationships that could have appeared to influence the work reported in this paper.

$\square$ The authors declare the following financial interests/personal relationships which may be considered as potential competing interests:

Declarations of interest: none. 
Click here to access/download

e-Component

Plum data 20191102.csv 